\title{
Bidirectional Modulation of Recognition Memory
}

\author{
Jonathan W. Ho, ${ }^{1}$ Devon L. Poeta, ${ }^{1}$ Tara K. Jacobson, ${ }^{1}$ Timothy A. Zolnik, ${ }^{2}$ Garrett T. Neske, ${ }^{2}$ Barry W. Connors, ${ }^{2}$ \\ and ${ }^{-R e b e c c a}$ D. Burwell ${ }^{1,2}$ \\ ${ }^{1}$ Department of Cognitive, Linguistic and Psychological Sciences and 2Department of Neuroscience, Brown University, Providence, Rhode Island 02912
}

Perirhinal cortex (PER) has a well established role in the familiarity-based recognition of individual items and objects. For example, animals and humans with perirhinal damage are unable to distinguish familiar from novel objects in recognition memory tasks. In the normal brain, perirhinal neurons respond to novelty and familiarity by increasing or decreasing firing rates. Recent work also implicates oscillatory activity in the low-beta and low-gamma frequency bands in sensory detection, perception, and recognition. Using optogenetic methods in a spontaneous object exploration (SOR) task, we altered recognition memory performance in rats. In the SOR task, normal rats preferentially explore novel images over familiar ones. We modulated exploratory behavior in this task by optically stimulating channelrhodopsin-expressing perirhinal neurons at various frequencies while rats looked at novel or familiar 2D images. Stimulation at $30-40 \mathrm{~Hz}$ during looking caused rats to treat a familiar image as if it were novel by increasing time looking at the image. Stimulation at $30-40 \mathrm{~Hz}$ was not effective in increasing exploration of novel images. Stimulation at $10-15 \mathrm{~Hz}$ caused animals to treat a novel image as familiar by decreasing time looking at the image, but did not affect looking times for images that were already familiar. We conclude that optical stimulation of PER at different frequencies can alter visual recognition memory bidirectionally.

Key words: brain oscillations; familiarity; novelty; optogenetics; perirhinal; vision

\section{Significance Statement}

Recognition of novelty and familiarity are important for learning, memory, and decision making. Perirhinal cortex (PER) has a well established role in the familiarity-based recognition of individual items and objects, but how novelty and familiarity are encoded and transmitted in the brain is not known. Perirhinal neurons respond to novelty and familiarity by changing firing rates, but recent work suggests that brain oscillations may also be important for recognition. In this study, we showed that stimulation of the PER could increase or decrease exploration of novel and familiar images depending on the frequency of stimulation. Our findings suggest that optical stimulation of PER at specific frequencies can predictably alter recognition memory.

\section{Introduction}

Recognition memory can be defined as judgment of the prior occurrence of an event (familiarity) accompanied by memory for the context in which the event occurred (recollection) (Mandler, 1980). Abundant evidence from animal and human studies shows that familiarity-based recognition is supported by the

Received June 13, 2015; revised Aug. 17, 2015; accepted Aug. 20, 2015.

Author contributions: J.W.H., T.K.J., T.A.Z., G.T.N., B.W.C., and R.D.B. designed research; J.W.H., D.L.P., T.K.J., T.A.Z., G.T.N., and R.D.B. performed research; J.W.H., D.L.P., T.K.J., T.A.Z., G.T.N., B.W.C., and R.D.B. analyzed data; J.W.H., T.K.J., B.W.C., and R.D.B. wrote the paper.

This work was supported by the National Science Foundation (Grant IOB-1146334 to R.D.B.), the National Institutes of Health (Grant 5-R01-NS050434 to B.W.C. and Grant F31-NS060448 to T.A.Z.), and the Defense Advanced Research Projects Agency (REPAIR Grant N66001-10-C-2010 to R.D.B. and B.W.C.).

The authors declare no competing financial interests.

Correspondence should be addressed to Dr. Rebecca D. Burwell, Department of Cognitive, Linguistic and Psychological Sciences, Brown University, 190 Thayer St., Providence, RI 02910. E-mail: rebecca_burwell@brown.edu.

J.W. Ho's present address: Department of Mechanical and Biomedical Engineering, City University of Hong Kong, Hong Kong, China, Kowloon.

T.A. Zolnik's present address: Humbolt University, Berlin, Germany 10117.

DOI:10.1523/JNEUROSCI.2278-15.2015

Copyright $\odot 2015$ the authors $\quad 0270-6474 / 15 / 3513323-13 \$ 15.00 / 0$ perirhinal cortex (PER) (Meunier et al., 1993; Mumby and Pinel, 1994; Brown and Xiang, 1998; Xiang and Brown, 1998; Brown and Aggleton, 2001; Winters et al., 2004; Gonsalves et al., 2005; Montaldi et al., 2006; Brown et al., 2010). PER neurons recorded in nonhuman primates exhibit decreases in firing rates as novel objects become familiar (Riches et al., 1991; Fahy et al., 1993; Brown and Xiang, 1998; Xiang and Brown, 1998; Hölscher et al., 2003; but see Thome et al., 2012). In rats, recording and imaging studies of the PER have identified visually responsive, repetitionsensitive neurons (Zhu et al., 1995; Wan et al., 1999; but see Burke et al., 2012). In addition to signaling novelty and familiarity, the PER also processes information about individual objects. PER firing rates exhibit behavioral correlates in object-guided memory and learning tasks (Lehky and Tanaka, 2007; Yanike et al., 2009) and PER neurons show selectivity for particular visual images (Naya et al., 2001; Sato and Nakamura, 2003), odors (Young et al., 1997), and 3D objects (Burke et al., 2012; Deshmukh et al., 2012).

The question of how the PER might code for novelty and familiarity while also coding for the identity of particular objects 
is currently under debate (Cowell et al., 2010; Lulham et al., 2011). One possibility is that relative novelty and object identity are both coded by firing rates. Another possibility is that one of these functions is coded by firing rates and the other by oscillatory or synchronized neuronal activity. Consistent with this idea, depth recordings in the human hippocampus showed that the power of brain oscillations in high-frequency bands, particularly low-gamma frequency bands, decreased as novel environments became familiar (Park et al., 2014). In rodents, exploration of novel objects was accompanied by increased power in the lowgamma frequency range (Lapray et al., 2009). Increased gamma power is also associated with increases of attention in humans (Herrmann and Knight, 2001; Debener et al., 2003; Fries, 2009) and exposure to novelty has been shown to increase attention (Lee et al., 2007; Marco-Pallarés et al., 2015). Depth recordings in humans also showed that the power of lower-frequency oscillations increased as novel environments become more familiar (Park et al., 2014). This is consistent with a prior rodent study in which spontaneous local field potentials (LFPs) in the PER showed a prominent oscillation in the $10-12 \mathrm{~Hz}$ (low-beta) frequency band in rats foraging in a familiar environment (Nerad and Bilkey, 2005). The $10-12 \mathrm{~Hz}$ oscillation disappeared when rats were transferred to a novel environment.

Here, we show that behavioral exploration of novel and familiar visual images can be modulated differentially by stimulating the PER at specific frequencies. Stimulation in the low-gamma frequency band increased exploration of familiar images and stimulation in the low-beta frequency band decreased exploration of novel images.

\section{Materials and Methods}

Subjects

Subjects were adult male Long-Evans rats weighing 250-300 g at the time of surgery. Rats were housed individually and maintained in a $12 \mathrm{~h}$ light/dark cycle. Animals were kept at $85-90 \%$ body weight of a naive animal and were allowed ad libitum access to water. All procedures were performed according to National Institutes of Health guidelines and were approved by Brown University's Institutional Animal Care and Use Committee.

\section{Viral vectors}

For viral transduction of the PER, pLenti-Synapsin-hChR2(H134R)EYFP-WPRE plasmid with an enhanced channelrhodopsin-2 (ChR2)EYFP fusion gene driven by a synapsin 1 promoter packaged into a VSV-G pseudotyped lentiviral vector at the University of Pennsylvania Vector Core was used. Plasmid maps are available at www.optogenetics. org. Viral titers were $\approx 10^{10} \mathrm{IU} / \mathrm{ml}$.

\section{Surgery}

Anesthesia was induced with 3\% isoflurane and maintained with 2.5$1.5 \%$ isoflurane throughout the surgical procedure. The rat was then secured in a stereotaxic frame in the flat skull position. An incision was made to expose the underlying skull. After attachment of anchor screws, craniotomies were made at appropriate sites for viral vector infusions, lesions, and implantations of fibers or optrode, depending on the study.

For animals used in the spontaneous object recognition (SOR) task in Study A $(n=8)$ and Study B $(n=11)$, a 24 G guide cannula (Plastics One) was used to guide infusion of the virus and placement of the fiber into caudal PER. The cannula was fixed above cortex and secured to the skull with bone cement (DePuy) at an angle of $12-13^{\circ}$ from vertical in a mediolateral plane $6.65 \mathrm{~mm}$ posterior to bregma and $5.1 \mathrm{~mm}$ lateral to the midline. Viral injections were made at a depth of $6 \mathrm{~mm}$ below skull through an infusion cannula connected to an infusion pump (Harvard Apparatus). The viral vector suspension was injected at a rate of 0.1 $\mu \mathrm{l} / \mathrm{min}$ for a total volume of virus injected into one hemisphere of $1 \mu \mathrm{l}$. After the $10 \mathrm{~min}$ infusion and a $5 \mathrm{~min}$ waiting time, the infusion cannula was slowly removed and replaced by an optical fiber inserted into the guide cannula such that the tapered fiber tip was centered in the transduced region. The optical fiber was then cemented into place with bone cement (DePuy) and the wound was closed by sutures. For excitotoxic lesions of the caudal PER contralateral to the vector and fiber, NMDA (250 mM dissolved in $0.5 \mathrm{~N} \mathrm{NaOH}$; Tocris Bioscience) was delivered by a pulled glass micropipette (30-50 $\mu \mathrm{m}$ outside tip diameters) by iontopheresis $(-6 \mu \mathrm{A}, 7 \mathrm{~s}$ on and $7 \mathrm{~s}$ off for $9 \mathrm{~min})$. Lesions were made at 4 locations: all 4 at $12-13^{\circ}$ from vertical in a mediolateral plane and $5.1 \mathrm{~mm}$ lateral from the midline, 2 at 6.35 , and 2 at $6.95 \mathrm{~mm}$ behind bregma at both 6.2 and $6.0 \mathrm{~mm}$ below the skull.

For animals used for in vitro recordings in Study C $(n=6)$, a viral vector injection was made unilaterally in caudal PER using the same coordinates as for Studies A and B. The viral vector suspension was pressure injected using a glass micropipette (30-50 $\mu \mathrm{m}$ outside tip diameter) at a rate of $0.1 \mu \mathrm{l} / \mathrm{min}$, for a total $1 \mu \mathrm{l}$ volume of virus injected into 1 hemisphere. After the infusion, the infusion cannula was removed slowly.

For animals used for in vivo recordings in Study D $(n=6)$, optrodes consisting of three tungsten FORMVAR-coated wires ( $25 \mu \mathrm{m}$ diameter) (A-M Systems) connected to an Omnetics connecter (Plexon) and an optical fiber were implanted. The wires were epoxied (Optical Adhesive 81; Norland Products) diametrically opposite one other onto an optical fiber such that the tips extended $500-750 \mu \mathrm{m}$ from the tip of the optical fiber. Before implantation of the optrode, $20.5 \mu$ lentiviral injections were made into caudal PER via a glass micropipette (30-50 $\mu$ m outside tip diameter) at a rate of $0.1 \mu \mathrm{l} / \mathrm{min}$. The injections were directed at an angle of $12^{\circ}$ from vertical in the mediolateral plane, 6.35 and $6.95 \mathrm{~mm}$ behind bregma, $5.1-5.35 \mathrm{~mm}$ from the midline, 6.2 and $6.0 \mathrm{~mm}$ below the skull. After completion of the final injection, the optrode was lowered into position at an angle of $12^{\circ}$ from vertical in a mediolateral plane, 6.65 $\mathrm{mm}$ posteror to bregma, $5.1-5.35 \mathrm{~mm}$ lateral to the midline, and $6.1 \mathrm{~mm}$ below the skull. The optrode was cemented into place using bone cement (DePuy). Three rats received viral injections and three served as untransduced controls.

After completion of the surgical procedures, animals were maintained on a calibrated $\left(37^{\circ} \mathrm{C}\right)$ heating pad until recovery from anesthesia before being returned to the vivarium. Rats were allowed to recover for at least $14 \mathrm{~d}$ to allow sufficient transduction of the viral vector.

\section{Histology}

ChR2 expression and the contralateral NMDA lesion were located between 6.6 and $7.1 \mathrm{~mm}$ posterior to bregma in caudal PER for all subjects in Studies A and B (Fig. 1c-f). For all subjects, the fiber tip was located at the center of the viral injection. Of the eight transduced rats used in Study A, the fiber implant was lost in one rat before any testing. In the remaining seven rats, median ChR2 expression in the rostrocaudal axis ranged from 480 to $1200 \mu \mathrm{m}$ in diameter. Contralateral to ChR2 and the fiber, excitoxic damage from NMDA injections was observed in all layers throughout the caudal PER (Fig. 1d). Of the 11 rats prepared for Study B, three were eliminated because of a broken optical fiber, no virus expression, or the lack of a contralateral lesion, respectively. Location of the virus for the remaining eight animals was similar to the locations in Study A, with ChR2 expression ranging from 450 and $1170 \mu \mathrm{m}$ in diameter. Contralateral to the ChR2-expressing site, damage was observed in all layers throughout caudal PER. There were cases in which damage extended slightly to the external capsule, postrhinal cortex, entorhinal cortex, or area $T e_{v}$, but these subjects were retained because damage was unilateral and it would not be expected to impair behavior (Hannesson et al., 2004; Barker and Warburton, 2011). Indeed, behavioral results reported below show that, in control (no stimulation) conditions in which a novel stimulus and a familiar stimulus were presented at choice, rats always showed normal discrimination, indicating that the unilateral lesion did not influence behavior. Of the 6 rats prepared for Study D, optical fibers were located in caudal PER between 5.64 and $-6.96 \mathrm{~mm}$ caudal to bregma $(n=6)$. As in Studies A and B, viral vector expression in the virus animals $(n=3)$ was colocalized with the fiber. No signs of photo-induced cell damage were observed in the transduced regions in any study. 

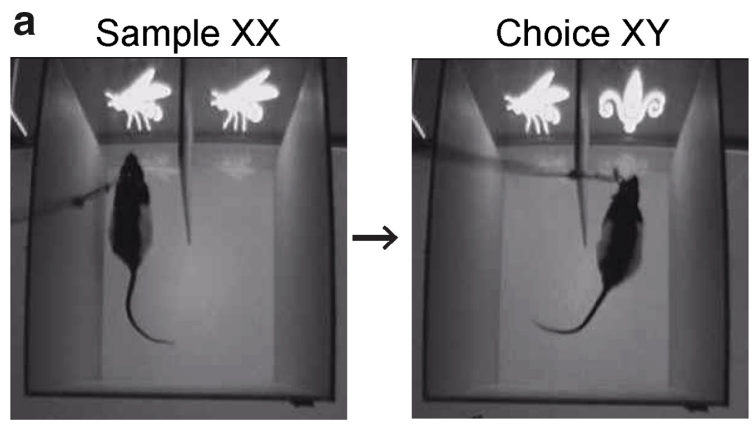

b

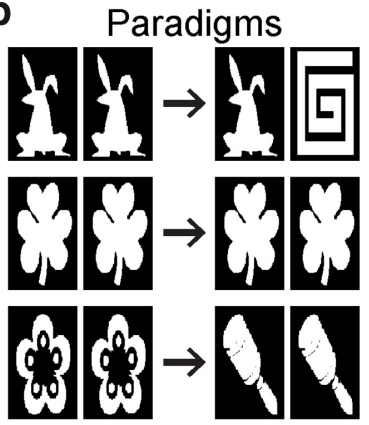

C

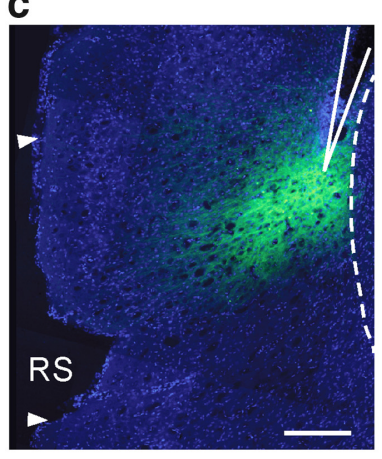

\section{d}

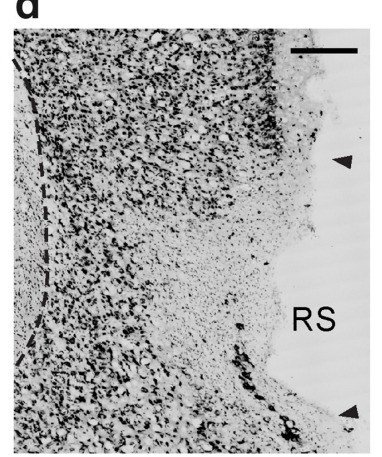

e
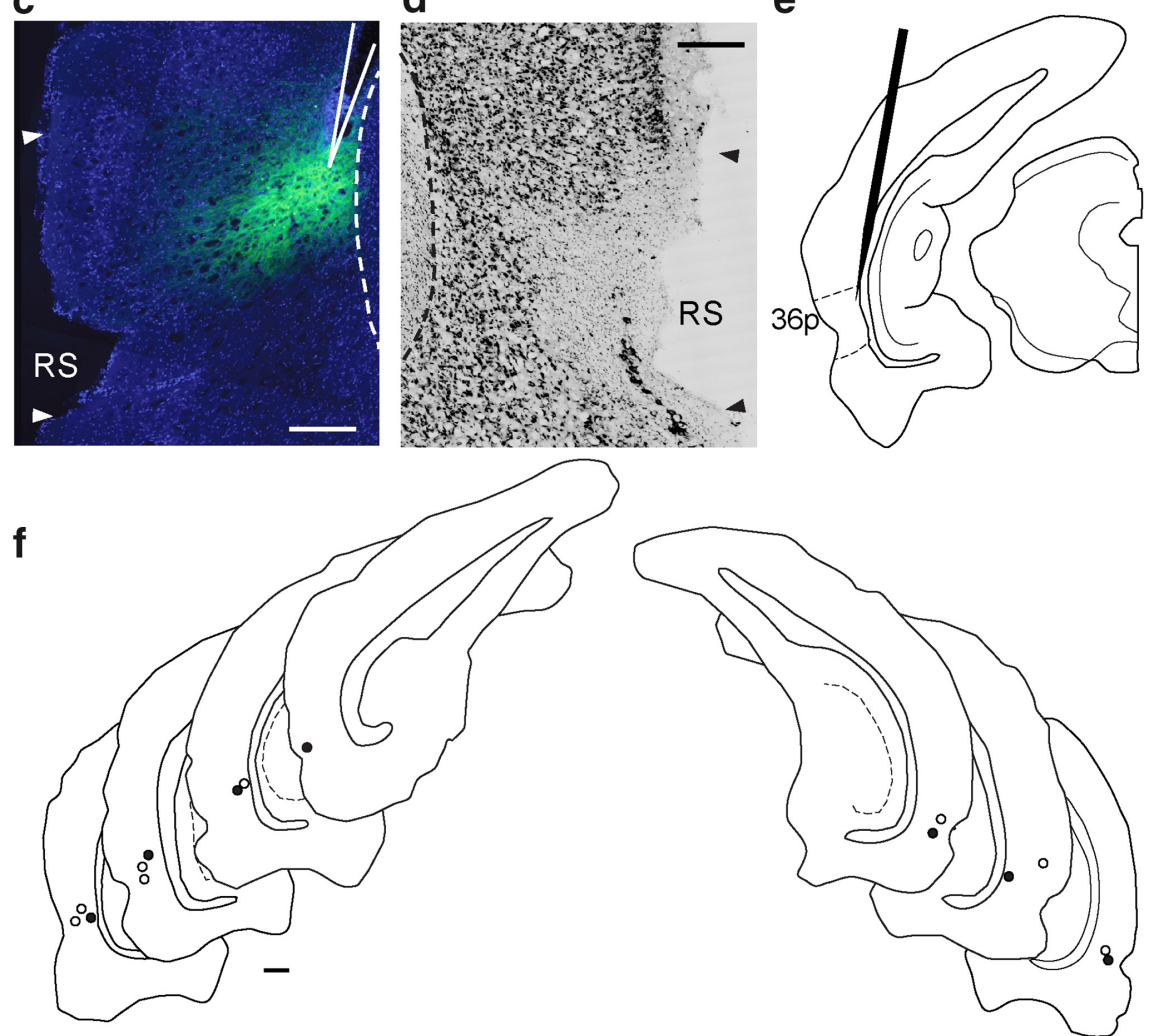

Figure 1. Experimental design and histology. $a$, Rat performing the SOR task. X represents the familiar image, i.e., presented in the sample and choice periods. Y represents the novel image, i.e., presented only in the choice period. A 5 min delay separated the two periods. $\boldsymbol{b}$, Three experimental paradigms. In all paradigms, two identical images (XX) were always presented in the sample period. The standard configuration was $X X \rightarrow X Y$. In some experiments, the two sample images were both presented again at choice $(X X \rightarrow X X)$. In other experiments, two novel identical images were presented at choice $(X X \rightarrow Y Y)$. c, Expression ofChR2-EYFP (green) in a 30- $\mu \mathrm{m}$-thick coronal section in caudal PER in a representative subject. Neurons are labeled with DAPI (blue). Position of the fiber is indicated. Scale bars: $\boldsymbol{c}, \boldsymbol{d}, 250 \mu \mathrm{m} \boldsymbol{d}$, Example of excitotoxic lesion for the same subject labeled for NeuN and counterstained for Nissl bodies. $\boldsymbol{e}$, Schematic of the location of the tapered optical fiber. $\boldsymbol{f}$, Contours showing locations of optical fiber tips. All fiber tips were located in caudal PER. The solid dots are for Study A and the open dots are for Study B. Scale bar, 500 $\mu \mathrm{m}$. RS, Rhinal sulcus; 36p, caudal PER area 36.

\section{SOR task}

Materials and apparatus. The SOR task was performed in a rectangular enclosure $(40 \mathrm{~L} \times 30 \mathrm{~W} \times 40 \mathrm{H} \mathrm{cm})$ open on the top and bottom. The side and back walls were composed of white acrylic. The front wall was transparent acrylic. An opaque divider $40 \mathrm{~cm}$ in height extended $15 \mathrm{~cm}$ from the front wall to divide the front of the arena into two equal compartments. The divider also extended $5 \mathrm{~cm}$ on the outside of the front panel. The SOR box was placed on a floor projection maze (Jacobson et al., 2014) and a gray floor was projected. Rats were monitored by an overhead video camera. For Study A, images were back projected (Epson) onto a vertical rear projection screen situated $5 \mathrm{~cm}$ beyond the front wall (Fig. 1a). For Study B, a standard monitor positioned at the same location as the rear projection screen was used. Black and white clipart images were obtained online (Microsoft). The projected images varied in complexity and were $\sim 10 \times 15 \mathrm{~cm}$ when displayed on the screen or monitor. Two images were projected simultaneously onto the screen directly in front of the transparent wall. Rats show preferential exploration of novel 2D images comparable to when $3 \mathrm{D}$ objects are used (Forwood et al., 2007).

Habituation. Rats were habituated to the testing room and arena for 3 consecutive days before the first day of testing. On each day of habituation, rats were handled for 5 min before habituation to the apparatus. On days 1-3, each rat was allowed to explore the arena for 5 min before being returned to its home cage. On day 2, the implanted optical fiber was coupled to the laser patch cord during habituation. On day 3 , the patch cord was connected and two images, not used for experiments, were presented during habituation.

Task procedures. The SOR task relies upon rats' innate preference for novelty and has been used extensively to study object recognition memory (Ennaceur and Delacour, 1988; Dix and Aggleton, 1999; Winters et al., 2008). In the present study, the task consisted of a sample and choice period separated by a 5 min delay in which the rat was returned to its home cage. In the sample period, 2 identical images were presented simultaneously in each compartment and the rat was allowed $15 \mathrm{~s}$ of active exploration of the images or $5 \mathrm{~min}$ in the arena, whichever was completed first. Active exploration of the images was scored for the first 3 min of the choice period.

For Studies A and B, three behavioral paradigms were used (Fig. 1b). In the standard $\mathrm{XX} \rightarrow \mathrm{XY}$ paradigm, two identical images were shown during the sample period and one of the two images was replaced by a novel image in the choice period. Two nonstandard paradigms were also used. In the first, the familiar images were simply presented again in the choice period (XX $\rightarrow \mathrm{XX}$ ). In the second, two identical novel images were presented in the choice period (XX $\rightarrow$ YY). With these three paradigms, optical stimulation could be used to interfere with preferential exploration of a novel image in the standard paradigm or to induce preferential exploration in the nonstandard paradigms.

Data analysis. Data acquisition, control over projection of the images, and control of the laser for stimulation were performed using Med Associates hardware and custom software written in Med State Notation (Med Associates). Two buttons on a button box interfaced with a SmartCTL Interface Module (DIG-716B; Med Associates) were used to signal active exploration. One button was used to record exploration of the image in the left compartment and the other to record exploration of the image in the right compartment. The first button press indicated the start of an exploration bout and the second button press indicated the end. During conditions in which optical stimulation was paired with looking, button presses resulted in custom software issuing TTL pulses to control laser stimulation trains at the appropriate frequency and pulse duration. Time stamps were saved in a data file. Information about exploration bouts and duration were extracted using MATLAB (The MathWorks). 
Exploration of the left and right images was coded by an experimenter who was blind to the experimental conditions. Active exploration was defined as a period when the rat's nose was past the central divider, its nose was directed toward the image, and it was not rearing or grooming. Preferential exploration of one image over another during the choice period was assessed by computing a discrimination ratio (DR) as the difference between the time exploring the images divided by the total exploration time. The DR measure was used because it takes into account individual differences in total exploration time (Bussey et al., 1999). Pilot experiments validating the scoring procedure were performed with two scorers blind to the experimental conditions. Recorded choice exploration times and obtained DRs were highly correlated across scorers (Pearson's correlation coefficient $=0.83$ and 0.86 , respectively).

Behavioral analysis. Two cohorts of rats were used for the SOR experiments (Study A and Study B). The order of experiments for both studies is shown in Table 1. In each cohort, the hemisphere that was optically stimulated was counterbalanced. Otherwise, all experiments used a within-subject, crossover design such that subjects were run once in each condition. For example, half the subjects would be subjected to the test condition in the first run and the control condition in the second run, whereas the second half of subjects would be subjected to the control condition followed by the test condition. When appropriate, which images were used as novel and familiar and the position of the novel image (left or right) were counterbalanced. When images were identical, the side of stimulation was counterbalanced. At least $48 \mathrm{~h}$ separated each run. Rats were removed from data analysis if ferrules or optical fibers broke or if optical fibers became disconnected during the task.

One-sample Student's $t$ tests were used to determine whether DRs differed significantly from zero. Our experiments were designed such that DRs would be positive if the results were in line with our predictions. Therefore, unless otherwise noted, tests for difference from zero were one-tailed. For differences in the DR, choice exploration times, exploratory bout number, and bout duration across conditions, repeatedmeasures ANOVA (rANOVA) with factors for condition (optogenetic (30 or $11 \mathrm{~Hz}$ ) vs control) and image type (novel vs familiar) was used. Level of significance was $p=0.05$. SEs were obtained from normalized means (Cousineau, 2005).

\section{Optical stimulation}

Caudal PER neurons were stimulated optogenetically at specific frequencies during the SOR task and control experiments. We chose caudal PER because it has the strongest connections with visual regions (Burwell and Amaral, 1998; Agster and Burwell, 2009). PER was transduced with the light-sensitive excitatory protein ChR2 for optical stimulation (Nagel et al., 2003; Boyden et al., 2005). For optical stimulation during in vivo experiments, we used multimode optical fibers (Polymicro Technologies; $200 \mu \mathrm{m}$ core, $0.22 \mathrm{NA}$ ). The fibers were pulled to a taper before implantation using a laser-based pipette puller (P2000; Sutter Instruments). Tapering minimized damage to the tissue and ensured that the light was diffused throughout the transduced tissue. All pulled fibers were tested before implantation and only fibers delivering light with at least $45 \%$ efficiency were implanted. Light was delivered by a $473 \mathrm{~nm}$ laser diode (Opto Engine) through a laser patch cord (Doric Lenses). The laser was controlled by TTL pulses issued by custom software and hardware coupled to the behavioral control system (SuperPort 16 Output Module, DIG-26TTL; Med Associates).

Depending on the experiment, optical stimulation parameters ranged from 5 to $60 \mathrm{~Hz}$ and from 4 to $12 \mathrm{~ms}$ pulse width. Fiber output was $\approx 12$ $\mathrm{mW}$. The laser and optical cable were tested before every experiment and the implanted optical fiber was examined before cabling each rat. If fibers were broken, the rat was removed from subsequent experiments.

In control conditions in which no stimulation was paired with either image, a laser patch cord was connected and exploration triggered laser operation identical to the experimental condition, but the light path from the laser patch cord into the implanted optical fiber was blocked physically. To keep the experimenter blind to condition, two patch cords were provided, one blocked and one capable of passing light. The experimenter was instructed as to which patch cord to use for each subject, but was not informed which patch cord was blocked. It should be noted that the patch cords were equipped with an opaque sleeve that completely occluded the light from both the rat and the experimenter. In addition, rats showed no overt behavioral sign or any sort of orienting to the stimulation that could alert the experimenter to the stimulation condition.

\section{Conditioned place preference task}

To determine whether stimulation at 30 or $11 \mathrm{~Hz}$ could be appetitive or aversive, an experiment was conducted to determine whether optical stimulation could support conditioned place preference. Two mazes were used, a horseshoe maze and a V-shaped maze, placed on the floor projection maze. The mazes were open on the top and bottom and were constructed of white acrylic with walls $40 \mathrm{~cm}$ high. Different greyscale patterns were back projected onto the floors of the east and west zones. The arms of the mazes were divided into three zones: east, west, and center. The position of the rat was tracked by CinePlex (Plexon) and the behavioral program was controlled by Med Associates hardware and custom software, as in other experiments. The stimulation parameters for 30 and $11 \mathrm{~Hz}$ were determined by calculating the means of the bout duration (laser ON duration) and interval between exploration bouts (interbout interval) from Experiments 1-4 of Study A. For the $30 \mathrm{~Hz}$ condition, the laser ON duration and the interbout interval was $486 \mathrm{~ms}$ and $20.574 \mathrm{~s}$, respectively; for the $11 \mathrm{~Hz}$ condition, the laser ON duration and the interbout interval was $460 \mathrm{~ms}$ and $21.344 \mathrm{~s}$, respectively. The laser was controlled by Med Associates hardware and custom software.

Each animal was conditioned and tested for a place preference twice, once in each maze and once with each frequency. Order of conditioning $(11 \mathrm{~Hz}$ and $30 \mathrm{~Hz})$ and the side of the maze on which optical stimulation was presented were counterbalanced. The conditioning procedure consisted of 4 sessions performed across 4 consecutive days. Each session lasted $15 \mathrm{~min}$.

In Session 1, rats were habituated to the maze. No optical stimulation was delivered and the rat was allowed to freely explore the whole maze. In Session 2, the rat was confined to one side of the maze and, in Session 3, the rat was confined to the other side. Optical stimulation was delivered in Session 2 or 3, counterbalanced for order (stimulation or no stimulation). In the test, Session 4, the partition was removed and rats were allowed to freely explore the east and west sides of the maze. The laser patch cord was attached to the implanted fiber in all four sessions, even though stimulation was presented only in Session 2 or Session 3. The maze floor was cleaned between subjects to remove odor cues.

For Session 4, the rat was placed in the center zone, and the session began when the rat exited this zone. The amount of time spent and number of entries into the east, center, and west zones were recorded. The experimenter was blind to stimulation condition. Results of the 11 $\mathrm{Hz}$ test and the $30 \mathrm{~Hz}$ test were analyzed separately. A two-tailed, paired $t$ test was used to compare time spent exploring the stimulation-paired side of the maze with time spent exploring the unpaired side of the maze.

\section{In vitro electrophysiology}

Rats were deeply anesthetized with isoflurane before being decapitated. The brain was quickly removed and $30-\mu \mathrm{m}$-thick horizontal sections containing the injection site were collected. Immediately after slice preparation, the slices were incubated at $32^{\circ} \mathrm{C}$ for $30 \mathrm{~min}$ and at room temperature for at least an additional $30 \mathrm{~min}$ before recording in a submersion chamber at $32^{\circ} \mathrm{C}$. The bathing solution (artificial CSF) used for recordings and brain slicing contained the following (in $\mathrm{mM}$ ): 126 $\mathrm{NaCl}, 1.25 \mathrm{NaH}_{2} \mathrm{PO}_{4}, 26 \mathrm{NaHCO}_{3}, 2 \mathrm{CaCl}_{2}$, and 10 dextrose saturated with $95 \% \mathrm{O}_{2} / 5 \% \mathrm{CO}_{2}$.

Whole-cell recordings were made with low-resistance (5-7 M $\Omega$ ) electrodes and the intracellular solution had the following composition (in mM): $130 \mathrm{~K}$-gluconate, $4 \mathrm{KCl}, 0.2$ EGTA, 10 HEPES, 4 ATP-Mg, 0.3 GTP-Tris, and 14 phosphocreatine-Tris. A MultiClamp 700B amplifier (Molecular Devices) was used for recordings. The series resistance was typically 6-20 M $\Omega$. Recordings were not corrected for the liquid junction potential.

Blue light stimulation with a spectral peak $\approx 470 \mathrm{~nm}$ was produced by a light-emitting diode (LED; M470L2-C1; Thorlabs) powered by a Thorlabs LEDD1B LED driver mounted on a dual lamp house adapter posi- 


\begin{tabular}{|c|c|c|c|}
\hline Study-Exp & Description & Images and conditions & Figure \\
\hline A-1 & $\begin{array}{l}30 \mathrm{~Hz} \text { optical stimulation increases exploration of a } \\
\text { familiar stimulus }(n=7)\end{array}$ & & $2 \mathrm{a}$ \\
\hline A-2 & $\begin{array}{l}30 \mathrm{~Hz} \text { optical stimulation increases exploration of a } \\
\text { familiar stimulus, but } 11 \mathrm{~Hz} \text { stimulation does not } \\
(\mathrm{n}=6)\end{array}$ & & $2 \mathrm{c}$ \\
\hline A-3 & $\begin{array}{l}11 \mathrm{~Hz} \text { optical stimulation decreases exploration of a } \\
\text { novel stimulus }(n=6)\end{array}$ & & $3 a$ \\
\hline A-4 & $\begin{array}{l}11 \mathrm{~Hz} \text { optical stimulation decreases exploration of a } \\
\text { novel stimulus }(n=6)\end{array}$ & & $3 \mathrm{c}$ \\
\hline A-5 & $\begin{array}{l}\text { Duration of pulse width is not responsible for effects } \\
(n=6)\end{array}$ & & $7 b$ \\
\hline A-6 & Stimulation does not affect activity $(\mathrm{n}=5)$ & & $7 \mathrm{a}$ \\
\hline A-7 & Novelty frequency screen: all familiar images $(n=4)$ & $40 \quad 11 \quad 6011$ & $4 b$ \\
\hline A-8 & Familiarity frequency screen: all novel images $(n=4)$ & NS & $4 \mathrm{a}$ \\
\hline B-1 & $\begin{array}{l}30 \mathrm{~Hz} \text { optical stimulation increases exploration of a } \\
\text { familiar image }(n=8)\end{array}$ & & $2 b$ \\
\hline B-2 & $\begin{array}{l}30 \mathrm{~Hz} \text { optical stimulation increases exploration of a } \\
\text { familiar image }(n=8)\end{array}$ & & $2 \mathrm{~d}$ \\
\hline B-3 & $\begin{array}{l}11 \mathrm{~Hz} \text { optical stimulation decreases exploration of a } \\
\text { novel image }(n=8)\end{array}$ & NS NS & $3 b$ \\
\hline B-4 & $\begin{array}{l}11 \mathrm{~Hz} \text { optical stimulation decreases exploration of a } \\
\text { novel image }(n=8)\end{array}$ & NS & $3 \mathrm{~d}$ \\
\hline B-5 & $\begin{array}{l}11 \mathrm{~Hz} \text { optical stimulation does not drive place } \\
\text { preference and appears not to be aversive }(n=8)\end{array}$ & $\begin{array}{l}11 \mathrm{~Hz} \text { stimulation vs. no stimulation } \\
\text { (NS) }\end{array}$ & $5 b, 1 e f t$ \\
\hline B-6 & $\begin{array}{l}30 \mathrm{~Hz} \text { optical stimulation does not drive place } \\
\text { preference and appears not to be rewarding }(n=8)\end{array}$ & $30 \mathrm{~Hz}$ stimulation vs. NS & $5 b$, right \\
\hline $\mathrm{C}$ & In vitro electrophysiology ( $n=29$ cells from 6 rats) & $10 \mathrm{~Hz}$ and $30 \mathrm{~Hz}$ stimulation & 6a-e \\
\hline $\mathrm{D}$ & In vivo electrophysiology $(n=6)$ & NS, $11 \mathrm{~Hz}$, and $30 \mathrm{~Hz}$ stimulation & 6f-h \\
\hline
\end{tabular}


tioned in the epifluorescence port of an Olympus BX50WI microscope. Light was delivered through a LUMPlanFl $40 \times / 0.80 \mathrm{~W}$ Olympus immersion objective and a FF655-Di01 (Semrock) dichroic mirror and produced a circular spot with a radius of $270 \mu \mathrm{m}$. The power output was $\approx 12.5 \mathrm{~mW}$ for the stimulation protocol.

\section{In vivo electrophysiology}

To characterize in vivo responses to 11 and $30 \mathrm{~Hz}$ stimulation, caudal PER was transduced with ChR2 as in other experiments and a custommade electrode with integrated optical fiber (optrode) was implanted at the virus transduced location (virus, $n=3$ ) or into untransduced PER (no virus, $n=3$ ). Neuronal activity recorded from our optrodes was multiplied 20 times with an operational amplifier at the head stage (HST/ 8o50-G20-GR; Plexon). Signals were then passed through a differential preamplifier with a gain of 12.5 (64-channel OmniPlex Amp; Plexon). Wide-band activity $(0-8 \mathrm{kHz})$ was recorded in awake animals at weeks 2 and 3 after viral injection during sessions in the SOR apparatus. Rats were allowed to explore, but no images were projected. Data were digitized at a sampling rate of $40 \mathrm{kHz}$. Recordings were obtained under 3 optical stimulation conditions: a no stimulation control, $3 \mathrm{~s}$ trains of $8 \mathrm{~ms}$ pulses of $11 \mathrm{~Hz}$ stimulation, and $3 \mathrm{~s}$ trains of $8 \mathrm{~ms}$ pulses of $30 \mathrm{~Hz}$ stimulation. In each session, the three conditions were presented three times. This was repeated 20 times for a total of 60 trials. The intertrial interval was $2 \mathrm{~s}$. Data and time stamps for test conditions were collected and analyzed offline with custom MATLAB programs (The MathWorks) using Chronux (www.chronux.org), an open source MATLAB toolbox. Multiunit activity (MUA) was extracted by high-pass filtering the wide-band signal to $>500 \mathrm{~Hz}$. To quantify the effect of optical stimulation, the number of peaks crossing a voltage threshold during each $3 \mathrm{~s}$ trial was determined. Threshold was 3 SDs above the mean voltage of the signal. Data for all trials during weeks 2 and 3 were combined. Outlier trials (trials with peaks $>3$ SDs above the mean for that session) were replaced with the mean for that condition.

\section{Results}

\section{$30 \mathrm{~Hz}$ optical stimulation of PER simulates novelty}

We first tested the hypothesis that $30 \mathrm{~Hz}$ optical stimulation of the PER could serve to simulate the effects of novelty on exploratory behavior (Fig. 2). In the first experiment of Study A $(n=7)$, we used the standard SOR task $(\mathrm{XX} \rightarrow \mathrm{XY}$ ) to test whether pairing exploration of the familiar image with $30 \mathrm{~Hz}$ optical stimulation would result in increased exploration of that image (Fig. 2a). In the control (no stimulation) condition, as expected, rats preferentially explored the novel image (Y) over the familiar image (X) $\left(\mathrm{DR}>0, t_{(6)}=3.6, p=0.005\right)$. In the experimental condition when the familiar image was paired with $30 \mathrm{~Hz}$ optical stimulation, rats did not preferentially explore the novel image $(\mathrm{DR} \approx 0$, $\left.t_{(6)}=-2.1, p=0.959\right)$. Therefore, rats appeared to treat the familiar image paired with $30 \mathrm{~Hz}$ stimulation as if it were novel. The control DR was significantly higher than the experimental $\operatorname{DR}\left(F_{(1,6)}=10.2, p=0.019\right)$.

Novel object exploration is often accompanied by increased duration of exploratory (looking) bouts (Renner and Seltzer, 1991). As would be expected, exploratory bouts of rats in the control condition were longer for novel $(600 \pm 20 \mathrm{~ms})$ than familiar images $(560 \pm 14 \mathrm{~ms})$. In the experimental condition, exploratory bout duration was longer for familiar images paired with the $30 \mathrm{~Hz}$ novelty signal $(614 \pm 27 \mathrm{~ms})$ than for unpaired novel images ( $507 \pm 25 \mathrm{~ms}$ ). This was confirmed by a condition by image type interaction $\left(F_{(1,7)}=8.9, p=0.021\right)$. Therefore, bout durations provided additional evidence that $30 \mathrm{~Hz}$ optical stimulation modulated novelty exploration or attention to novelty.

We replicated these findings with a second cohort of rats (Study B, $n=8$ ). Again, looking at a familiar image paired with 30 $\mathrm{Hz}$ optical stimulation resulted in increased exploration (Fig. $2 b$,
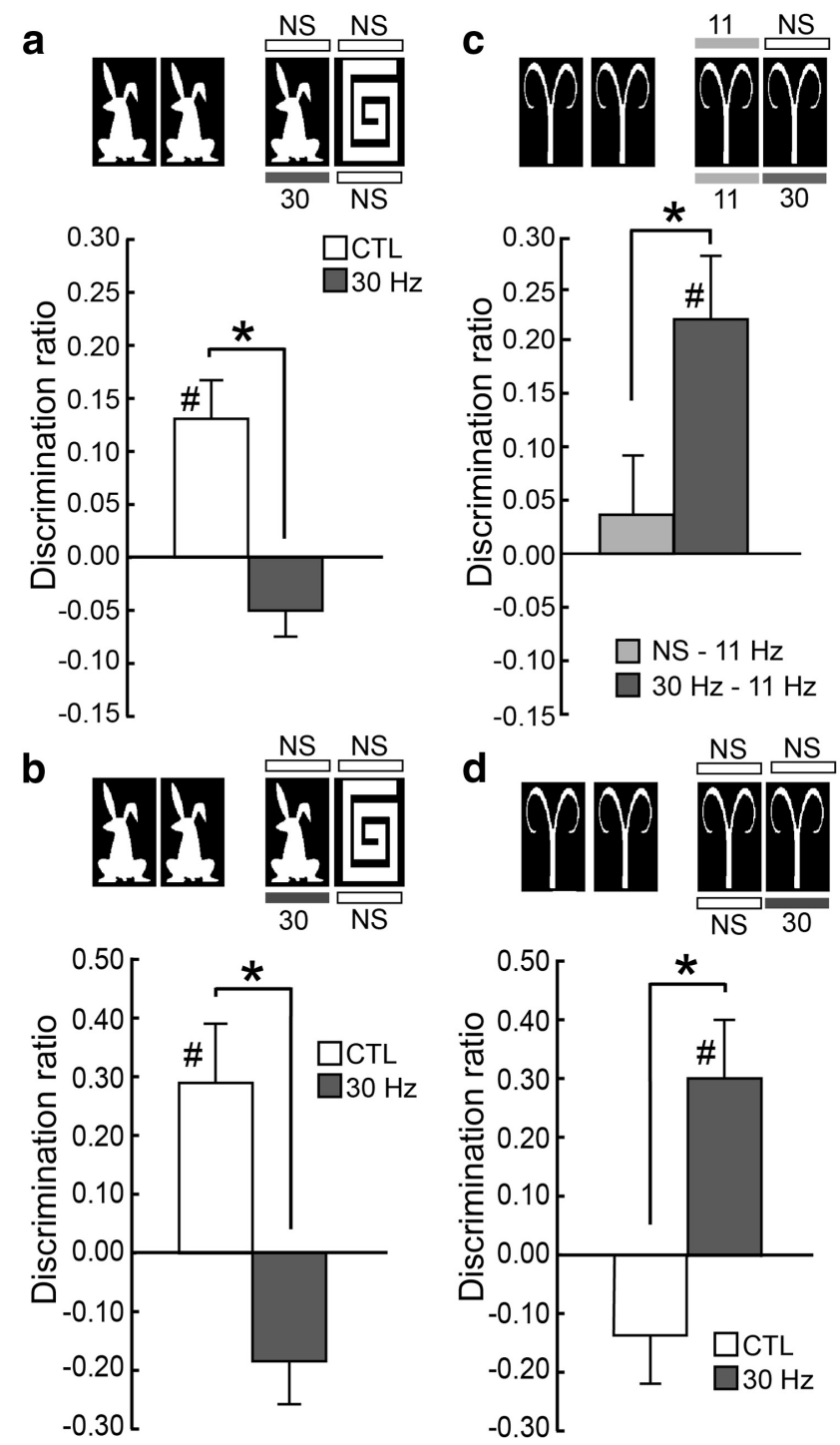

Figure 2. Optical stimulation at $30 \mathrm{~Hz}$ results in increased exploration of familiar images. Paradigms used are shown above the bar graphs. Stimulation was paired with exploration of images (looking) in the choice period. Control conditions (CTL) are above the images and experimental conditions (EXP) are below the images. An empty box indicates no stimulation (NS). For CTL conditions, the laser was connected and operated exactly as in the EXP condition, but light was physically blocked from entering the fiber. Side was always counterbalanced, but for illustration purposes, choice images on the left and right represent familiar/novel $(\boldsymbol{a}, \boldsymbol{b})$ or familiar/familiar-paired images $(\boldsymbol{c}, \boldsymbol{d})$, respectively. Therefore, in all panels, the image and stimulation condition in which greater exploration was expected is shown on the right such that $\mathrm{DR}=(\mathrm{R}-\mathrm{L}) /(\mathrm{R}+\mathrm{L}) \cdot \boldsymbol{a}$, In CTL, as expected, rats $(n=7)$ preferentially explored the novel image. In EXP, when the familiar image was paired with $30 \mathrm{~Hz}$ optical stimulation, rats spent similar amounts of time exploring the paired familiar image and the novel image. The CTL DR was significantly higher than the EXP DR. $\boldsymbol{b}$, Experiment in $\boldsymbol{a}$ was replicated with a second cohort of rats $(n=8)$. In CTL, again, rats explored the novel image more than the familiar one. In EXP, when looking at a familiar image was paired with $30 \mathrm{~Hz}$ stimulation, rats explored the familiar image more as if it were novel. c, In CTL, stimulation at $11 \mathrm{~Hz}$ does not decrease exploration of an already familiar stimulus. In EXP, stimulation at $30 \mathrm{~Hz}$ increased exploration of the paired familiar image $(n=6)$, showing that modulation of novelty exploratory behavior is frequency dependent. $\boldsymbol{d}$, Replication of $\boldsymbol{c}$ except that NS is compared with $30 \mathrm{~Hz}(n=8)$. Data are means \pm normalized SEM. ${ }^{*} p<0.05 ; \# p<0.05$ ( $t$ test), significant difference from zero.

Table 1). During the control condition, rats preferentially explored the novel image over the familiar image $\left(\mathrm{DR}>0, t_{(7)}=\right.$ $2.4, p=0.024)$. In the experimental condition, the rats preferentially explored the familiar image that was paired with $30 \mathrm{~Hz}$ optical stimulation $\left(\mathrm{DR}<0, t_{(7)}=-2.5, p=0.020\right)$. The differ- 
ence between DRs in the control and experimental conditions was, again, significant $\left(F_{(1,7)}=8.0, p=0.026\right)$. Exploratory bout duration was numerically longer for the novel image ( $379 \pm 11$ $\mathrm{ms})$ over the familiar image in the control condition ( $333 \pm 23$ $\mathrm{ms})$. In the experimental condition, bout duration was numerically longer for the familiar image paired with $30 \mathrm{~Hz}(508 \pm 67$ $\mathrm{ms}$ ) compared with the unpaired novel image (418 $\pm 67 \mathrm{~ms})$.

We further addressed the hypothesis that $30 \mathrm{~Hz}$ stimulation of PER could simulate novelty by pairing stimulation with one of two identical familiar images. In this experiment, we also confirmed that the frequency of stimulation is important for driving exploration. We used a paradigm in which the same two identical familiar images were presented during the sample and the choice periods (XX $\rightarrow \mathrm{XX}$; Fig. 2c). In the control condition, exploration of one familiar image was paired with $11 \mathrm{~Hz}$ stimulation, an LFP frequency associated with exploration of familiarity (Nerad and Bilkey, 2005). Exploration of the other identical familiar image was not accompanied by optical stimulation. If $11 \mathrm{~Hz}$ simulates familiarity, then $11 \mathrm{~Hz}$ stimulation paired with a familiar image should be redundant. In the experimental condition, exploration of one familiar image was paired with $30 \mathrm{~Hz}$ stimulation and exploration of the other identical familiar image was paired with $11 \mathrm{~Hz}$ stimulation. In the control condition, exploration did not differ significantly between the $11 \mathrm{~Hz}$ and NS stimulation conditions $\left(\mathrm{DR} \approx 0 ; t_{(5)}=0.7, p=0.258\right)$. In the experimental condition, however, rats explored the familiar image paired with $30 \mathrm{~Hz}$ significantly more than the familiar image paired with $11 \mathrm{~Hz}$ $\left(\mathrm{DR}>0 ; t_{(5)}=3.7, p=0.007\right)$. Therefore, rats again treated a familiar image paired with $30 \mathrm{~Hz}$ optical stimulation as novel.

The mean exploratory bout duration during exploration was longer for familiar objects paired with $30 \mathrm{~Hz}$ stimulation (763 \pm $66 \mathrm{~ms}$ ) compared with familiar objects paired with $11 \mathrm{~Hz}$ in the experimental condition $(598 \pm 39 \mathrm{~ms})$. In the control condition, bout duration was similar for the familiar image paired with 11 $\mathrm{Hz}(496 \pm 15 \mathrm{~ms})$ and the unpaired familiar image (528 \pm 17 $\mathrm{ms})$. This was confirmed by rANOVA showing a significant condition by image interaction $\left(F_{(1,6)}=14.0, p=0.019\right)$.

We replicated these findings in a second cohort of animals $(n=8)$ with a slightly altered experimental design (Fig. $2 d)$. There was no stimulation in the control condition. For the experimental condition, exploration of one of the identical familiar images was paired with $30 \mathrm{~Hz}$ stimulation and the other was not paired with stimulation. For rats in the no stimulation control condition, exploration of the images was not significantly different $\left(\mathrm{DR} \approx 0 ; t_{(7)}=-1.7, p=0.065\right)$. In the experimental condition, rats preferentially explored the familiar image paired with $30 \mathrm{~Hz}$ stimulation compared with the unpaired identical familiar image $\left(\mathrm{DR}>0 ; t_{(7)}=2.4, p=0.025\right)$. The $\mathrm{DR}$ in the experimental condition differed significantly from the control condition $\left(F_{(1,7)}=7.2, p=0.031\right)$. Exploratory bout durations were no different in the control condition ( $452 \pm 59$ and $357 \pm 32 \mathrm{~ms})$. For the experimental condition, exploratory bouts were numerically, though not significantly, longer when exploration of the familiar image was paired with $30 \mathrm{~Hz}$ stimulation $(1170 \pm 762$ $\mathrm{ms})$ compared with the unpaired image (302 $\pm 49 \mathrm{~ms})$.

\section{$11 \mathrm{~Hz}$ optical stimulation of PER simulates familiarity}

We tested directly the hypothesis that $11 \mathrm{~Hz}$ optical stimulation of PER could simulate the effects of familiarity on exploratory behavior. In the standard SOR task (XX $\rightarrow \mathrm{XY}$; Fig. 3a), rats in the no stimulation control condition preferentially explored the novel image more than the familiar image during the choice pe$\operatorname{riod}\left(\mathrm{DR}>0, t_{(5)}=3.3, p=0.011\right)$. When exploration of the
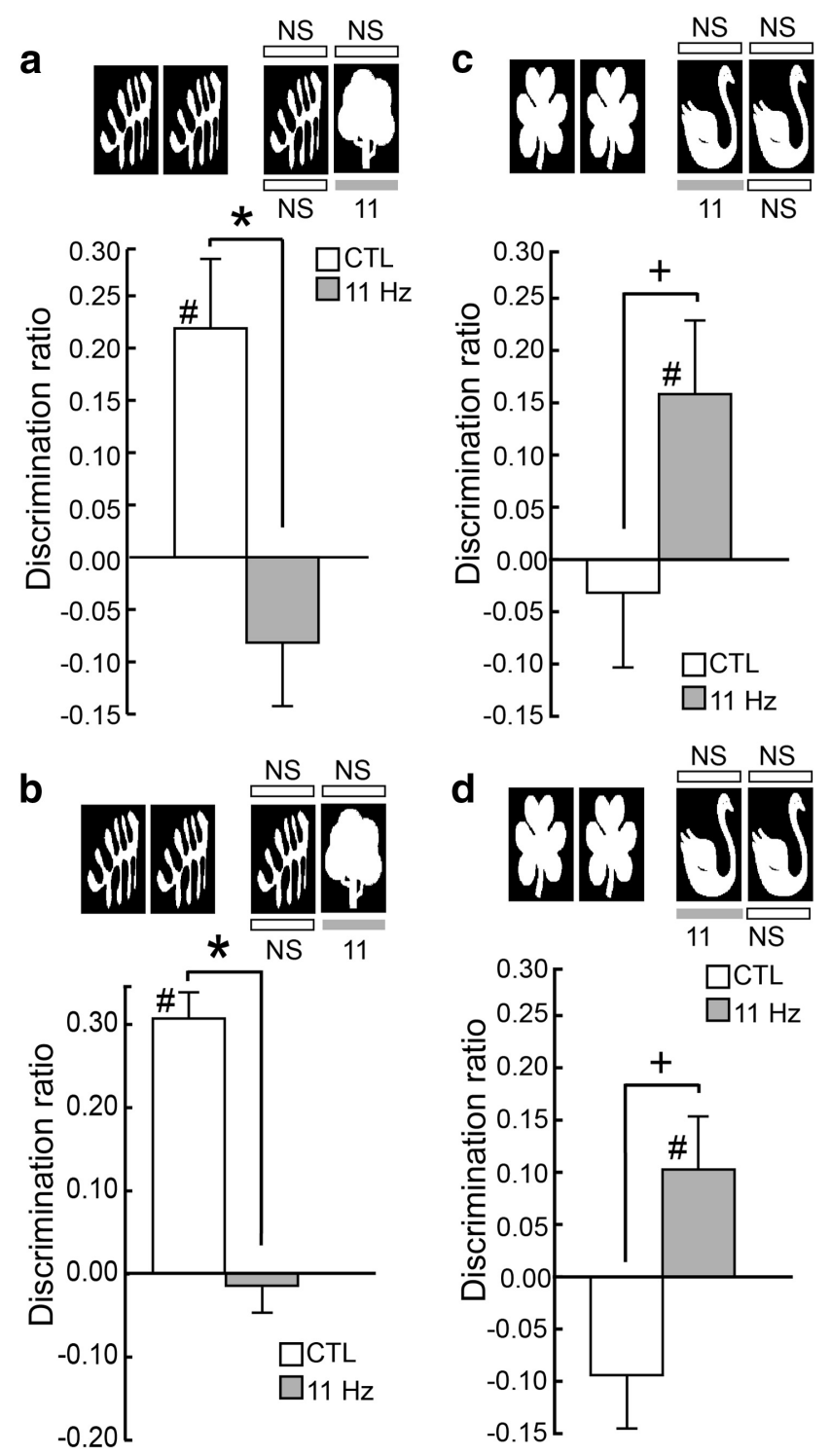

Figure 3. Optical stimulation at $11 \mathrm{~Hz}$ results in decreased exploration of novel images. As for Figure 2, paradigms are shown above the bar graphs. Stimulation was paired with exploration of image(s) in the choice period (the two right panels in each set of four). Control conditions (CTL) are above the images and experimental conditions (EXP) are below. An empty box indicates no stimulation (NS). For CTL, the laser was connected and operated exactly as in the experimental condition, but light was physically blocked from entering the fiber. For illustration, left and right choice images represent familiar/novel images $(\boldsymbol{a}, \boldsymbol{b})$ or novel-paired/novel images $(\boldsymbol{c}, \boldsymbol{d})$, respectively. Therefore, in all panels, the image and stimulation condition in which greater exploration was expected is shown on the right such that $D R=(R-L) /(R+L)$. $\boldsymbol{a}$, In CTL, rats $(n=7)$ discriminated normally. In EXP, when optical stimulation at $11 \mathrm{~Hz}$ was paired with looking at the novel image, rats explored the familiar image and the novel paired image equally. $\boldsymbol{b}$, Replication of $\boldsymbol{a}(n=8)$. c, In CTL, rats $(n=6)$ explore the two novel images equally. In EXP, stimulation at $11 \mathrm{~Hz}$ decreased exploration of the paired novel image $(n=6)$. $\boldsymbol{d}$, Replications of $\boldsymbol{c}(n=8)$. Data are means \pm normalized SEM. ${ }^{*} p<0.05 ;+p<0.10$ (rANOVA); $\# p<0.05$ ( $t$ test), significant difference from zero.

novel image was paired with $11 \mathrm{~Hz}$ optical stimulation, however, rats explored the paired novel and familiar images for similar amounts of time, suggesting that the rats were treating the novel image paired with $11 \mathrm{~Hz}$ stimulation as if it were also familiar $\left(\mathrm{DR} \approx 0 ; t_{(5)}=-1.3, p=0.882\right)$. The $\mathrm{DRs}$ in the two conditions were significantly different $\left(F_{(1,5)}=12.7, p=0.016\right)$. Bout durations in the control condition were numerically longer for the novel image over the familiar image (567 \pm 126 over $399 \pm 64)$. 
Bout durations in the experimental condition were about the same for the unpaired novel image and for the novel image paired with $11 \mathrm{~Hz}(507 \pm 37$ vs $475 \pm 12 \mathrm{~ms}$, respectively).

These findings were replicated with a second cohort of animals (Study B). In Study A, variability was greater for the $11 \mathrm{~Hz}$ stimulation experiments compared with $30 \mathrm{~Hz}$, so in these replications, subjects were run twice in each condition. For the $\mathrm{XX} \rightarrow$ XY paradigm (Fig. 3b), 1 rat was removed due to an error in data collection $(n=7)$. Rats in the control condition preferentially explored the novel image over the familiar image (DR $>0 ; t_{(6)}=$ $6.2 ; p=0.0004)$. In the experimental condition, rats did not explore the novel image paired with $11 \mathrm{~Hz}$ stimulation more than the unpaired familiar image $\left(\mathrm{DR} \approx 0 ; t_{(6)}=-0.2 ; p=0.585\right)$. Bout durations in the control condition were numerically higher for the novel image over the familiar image $(739 \pm 279$ over $615 \pm 297 \mathrm{~ms})$. Bout durations in the experimental condition were, again, about the same for the unpaired familiar image and for the novel image paired with $11 \mathrm{~Hz}(387 \pm 61 \mathrm{vs} 384 \pm 21 \mathrm{~ms}$, respectively).

We further tested the hypothesis that familiarity is simulated by $11 \mathrm{~Hz}$ stimulation in a complementary experiment; in this case both images in the choice period were identical and novel (XX $\rightarrow$ YY; Fig. 3c). As expected, rats explored the novel images equally during choice in the no stimulation control condition $(\mathrm{DR} \approx 0$; $\left.t_{(5)}=-0.4, p=0.338\right)$. In the experimental condition, we paired exploration of one of the novel images with $11 \mathrm{~Hz}$ optical stimulation. Pairing the novel image with $11 \mathrm{~Hz}$ stimulation reduced exploration compared with the identical unpaired novel image $\left(\mathrm{DR}>0 ; t_{(5)}=2.2, p=0.037\right)$. The difference in DRs between the $11 \mathrm{~Hz}$ and control conditions was also marginally significant (rANOVA: $\left.F_{(1,5)}=4.1, p=0.099\right)$. Bout durations were similar for the two novel images in the control condition $(513 \pm 24$ and $479 \pm 18 \mathrm{~ms}$ ). Bout duration was numerically longer for the unpaired novel image compared with the novel image paired with $11 \mathrm{~Hz}(499 \pm 47$ vs $445 \pm 22 \mathrm{~ms})$. Together, these findings suggest that animals treated the novel image as familiar when it was paired with $11 \mathrm{~Hz}$ optical stimulation.

These findings were replicated with a second cohort of rats (Study B, $n=8$; Fig. 3d). Again, rats in the control condition explored two identical novel images equally during choice $\left(\mathrm{DR} \approx 0 ; t_{(7)}=-1.5 ; p=0.911\right)$. In the experimental condition, rats explored the novel image paired with $11 \mathrm{~Hz}$ stimulation less than the identical unpaired novel image $(\mathrm{DR}>0$, $\left.t_{(7)}=2.3 ; p=0.026\right)$. As before, bout durations were similar in the control condition ( $498 \pm 36$ and $492 \pm 57 \mathrm{~ms}$ ). In the experimental condition, bout duration was numerically longer for the unpaired over the $11 \mathrm{~Hz}$ paired novel image (584 \pm 49 over $510 \pm 28 \mathrm{~ms}$ ).

High- and low-frequency stimulation have differential effects on exploratory behavior

The results described above imply that the frequency of stimulation is important for modulating exploration of novel and familiar images. To determine the optimal frequencies, we used a single-trial SOR task to test the efficacy of a range of optical stimulation frequencies. In the prior experiments, $11 \mathrm{~Hz}$ decreased exploration of novelty. Therefore, we examined the efficacy of frequencies ranging from 5 to $60 \mathrm{~Hz}$ for decreasing exploration of novelty. A new pair of identical novel images was used to test each frequency. Exploration of one novel image was not paired with stimulation (no stimulation, NS) and the identical novel image was paired with the "familiarity" test frequency (Stim). Therefore, the DR was calculated as DR $=(\mathrm{NS}-\mathrm{Stim}) /$
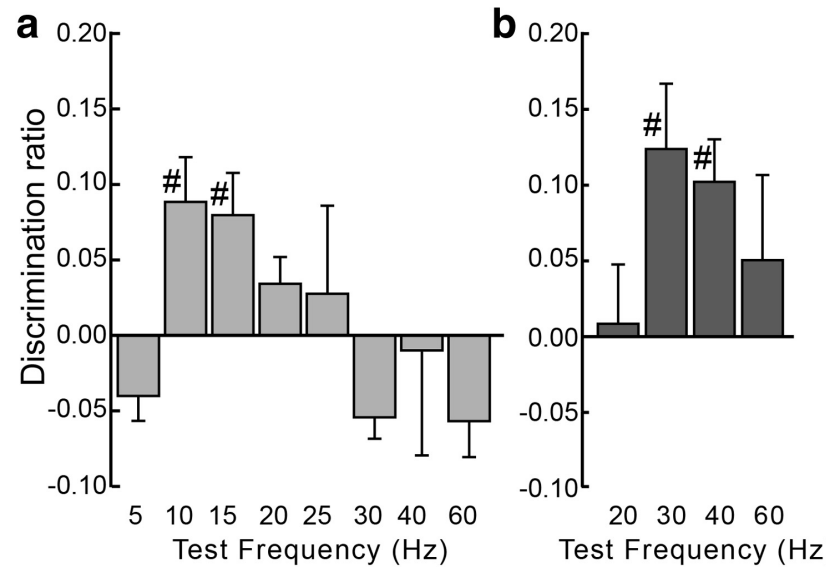

Figure 4. Screening for the most effective optical stimulation frequencies for decreasing exploration of novel images and increasing exploration of familiar images. $\boldsymbol{a}$, The 10 and $15 \mathrm{~Hz}$ frequency stimulation were effective for decreasing exploration of novelty. In each trial, both images were novel and identical; one was not paired with optical stimulation (NS) and the other was paired with stimulation $(5-60 \mathrm{~Hz}) . \mathrm{DR}=(\mathrm{NS}-\mathrm{Stim}) /(\mathrm{NS}+\mathrm{Stim})$ such that a positive DR indicates an effective frequency. $\boldsymbol{b}$, The 30 and $40 \mathrm{~Hz}$ frequency stimulation were effective for increasing exploration of familiar images. Both images used were familiar; one was paired with $10 \mathrm{~Hz}$ to ensure baseline familiarity and the other was paired with a range of stimulation frequencies $(20-60 \mathrm{~Hz})$. DR $=(\mathrm{Stim}-10 \mathrm{~Hz}) /(\mathrm{Stim}+10 \mathrm{~Hz})$ such that a positive DR indicated an effective frequency. Data are means \pm SEM. \#p $<0.05$, one-tailed Student's $t$ test $(n=4)$.

$(\mathrm{NS}+\mathrm{Stim})$, such that $\mathrm{DR}>0$ indicates preferential exploration of the unpaired novel image over the identical novel image paired with optical stimulation (Fig. $4 a$ ). We found that pairing exploration of a novel image with 10 or $15 \mathrm{~Hz}$ stimulation significantly reduced exploration of that image compared with the unpaired novel image ( $\mathrm{DR}>0, p<0.035)$. The other frequencies were ineffective in decreasing exploration of the novel image $(p>$ $0.05)$.

We also used the single-trial SOR paradigm to find optimal frequencies for increasing exploration of familiar images. In the prior experiments, $30 \mathrm{~Hz}$ increased exploration. Therefore, we used novelty test frequencies of 20,30,40, and $60 \mathrm{~Hz}$ (Fig. 4b). Familiar test images were images that had been used in earlier experiments. To ensure a baseline of familiarity, we compared each of the test frequencies (T) with $10 \mathrm{~Hz}$ stimulation (F) because this was the most effective frequency for simulating familiarity. Therefore, $\mathrm{DR}=(\mathrm{T}-\mathrm{F}) /(\mathrm{T}+\mathrm{F})$ and a $\mathrm{DR}$ significantly greater than zero would indicate preferential exploration of the image paired with the novelty test stimulation frequency, that is, it would be effective in increasing exploration of a familiar stimulus. We found that pairing exploration of a familiar image with 30 or $40 \mathrm{~Hz}$ optical stimulation significantly increased exploration of that image compared with the unpaired identical familiar image (DR $>0 ; p<0.032)$. The 20 and $60 \mathrm{~Hz}$ test frequencies were ineffective $(p>0.05$; Fig. $4 b)$.

\section{Effects of optical stimulation cannot be explained by valence of stimuli}

One possible explanation for our results is that PER stimulation at these frequencies is intrinsically aversive or rewarding. To test this, we used a conditioned place preference paradigm (Study B). After preconditioning in Session 1, rats were conditioned to one side of the maze in either Session 2 or Session 3 (Fig. $5 a$ ). In Session 4, rats were tested for a place preference. We compared time spent exploring the side of the maze that had been paired with the unpaired side of the maze using a two-tailed, paired $t$ 

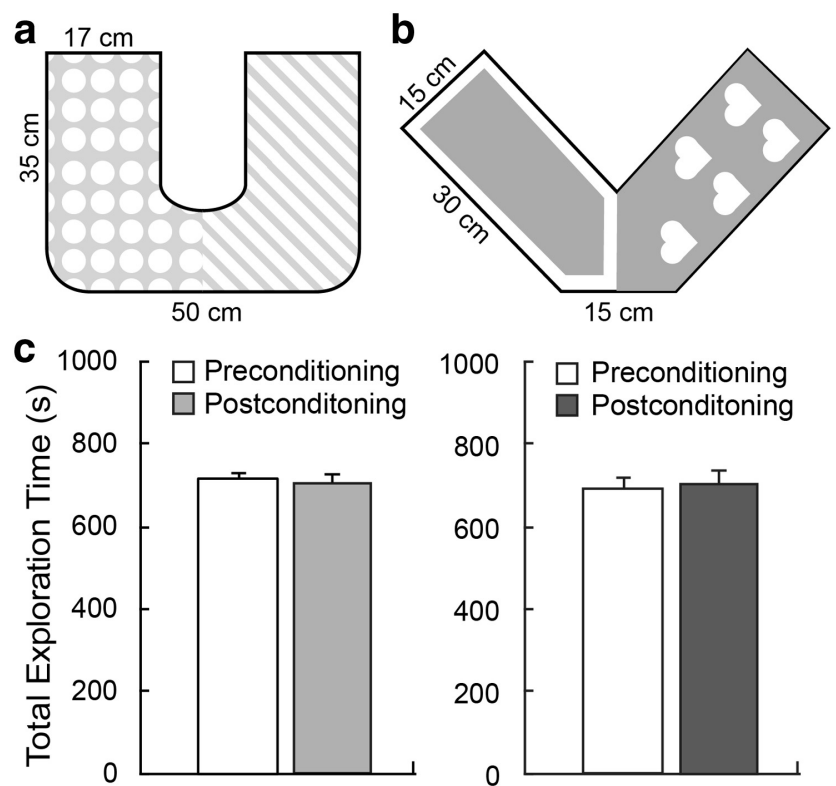

$11 \mathrm{~Hz}$ Test

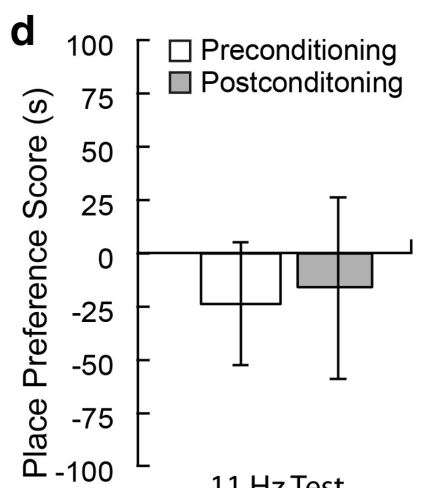

$11 \mathrm{~Hz}$ Test
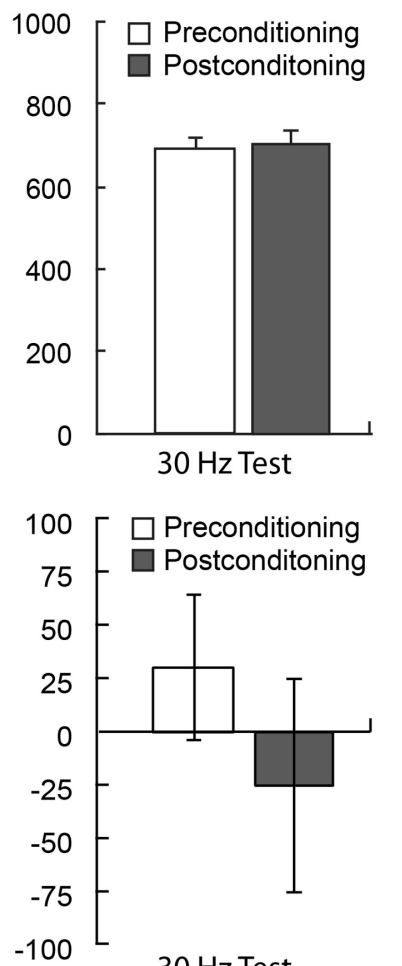

$30 \mathrm{~Hz}$ Test

Figure 5. PER stimulation at 11 or $30 \mathrm{~Hz}$ does not result in place preference or avoidance. $\boldsymbol{a}$, $\boldsymbol{b}$, Schematic showing the floor patterns and dimensions of the horseshoe maze $(\boldsymbol{a})$ and the $\mathrm{V}$ maze (b). c, Total exploration time for the unpaired (No Stim) and paired (Stim) sides of the mazes during the postconditioning test for 11 and $30 \mathrm{~Hz}(n=7)$. $\boldsymbol{d}$, Place preference scores for the rats during preconditioning and the postconditioning test for 11 and $30 \mathrm{~Hz}$. Neither frequency resulted in a place preference or a place avoidance.

test. For the $11 \mathrm{~Hz}$ test (Fig. $5 b$, left), rats showed no preference for the paired or the unpaired side $\left(t_{(7)}=0.43, p=0.68\right)$. Likewise, for the $30 \mathrm{~Hz}$ test (Fig. $5 b$, right), rats showed no preference for the paired or the unpaired side $\left(t_{(7)}=0.46, p=0.66\right)$.

\section{Cellular effects of optical stimulation: in vitro and in vivo studies}

To characterize the cellular effects of our optical stimulation protocol, we recorded from neurons in slices of PER maintained in vitro. Slices were obtained from rats that had been injected with ChR2-EYFP-transducing lentiviral vector at least 2 weeks earlier $(n=6)$, the minimum incubation period of the lentiviral vectors before behavioral experiments. Imaging of EYFP fluorescence in the live slices indicated expression in layers 2 through 6 . Wholecell current-clamp or voltage-clamp recordings were made from physiologically identified pyramidal cells in layers 2 through 6 within ChR2-expressing regions of PER $(n=29)$. The sampled neurons had regular-spiking properties (Beierlein et al., 2003) with a mean input resistance of $127 \pm 12 \mathrm{M} \Omega$ and resting membrane potentials of $-72 \pm 1.5 \mathrm{mV}$. Whole-field $(\sim 500 \mu \mathrm{m}$ in

diameter) light pulses ( $8 \mathrm{~ms}$ duration) were applied to stimulate the local network.

Of 29 neurons tested, 26 responded to light stimuli (Fig. 6); the three nonresponsive cells were recorded from regions with relatively weak fluorescence. In general, the robustness of lightevoked responses across neurons correlated well with the EYFP fluorescence in the region of the recording. ChR2-expressing and non-ChR2-expressing neurons (Fig. $6 a, b$ ) were identified by the latency of their light-evoked changes in membrane potential or current (Cruikshank et al., 2010). Twelve cells expressed ChR2 directly and generated large amplitude depolarizations (mean maxima of $72 \mathrm{mV}$ ) with very short latency ( $\leq 1 \mathrm{~ms}$ ) (Fig. $6 c$ ). Four of these ChR2-expressing cells reliably generated action potentials in response to light stimuli (Fig. $6 a$ ); two of them spiked in response to every stimulus at frequencies from $10 \mathrm{~Hz}$ to $60 \mathrm{~Hz}$. The other eight cells generated short-latency, variably sized depolarizations that did not reach spike threshold when tested at resting potential. Another 14 neurons within the ChR2expressing regions of PER did not express ChR2 themselves, but responded to light with synaptic events at onset latencies $>3 \mathrm{~ms}$ (Fig. 6b). Synaptic events can be triggered by ChR2 activation in both somatodendritic and axon terminal membranes (Cruikshank et al., 2010; Cruikshank et al., 2012). Responses of nonChR2-expressing neurons usually included combinations of excitatory and inhibitory postsynaptic events, as deduced by the polarity of the long-latency responses when varying the cells' holding potentials between -80 and $-20 \mathrm{mV}$ under voltageclamp conditions.

Most cells were also tested with trains of $10-40 \mathrm{~Hz}$ light pulses while steady, low-frequency firing was induced with continuous current injection. In seven ChR2-expressing neurons, light pulses could trigger and entrain spiking at rates higher than their prestimulus baseline rates. In seven other neurons, most of them non-ChR2 expressing, similar light trains induced mixed effects or a net inhibition of baseline spiking rates (Fig. $6 d$ ). Voltage clamping in these same neurons revealed light-induced IPSCs. In current-clamp conditions, after termination of $10-40 \mathrm{~Hz}$ light trains, the membrane of most cells hyperpolarized for durations of $0.5-10 \mathrm{~s}$ (depending on train length and frequency; Fig. 6e), during which baseline spiking ceased or slowed. Post-light-train afterhyperpolarizations (AHPs) were observed in both ChR2expressing and non-ChR2-expressing neurons, and the AHPs did not depend on light-evoked action potentials in the recorded cells (Fig. 6d). When brief suprathreshold current pulses were substituted for light pulses in $10-40 \mathrm{~Hz}$ stimulus trains, neurons also generated AHPs that suppressed spiking. Light-induced AHPs were longer and more robust than current-induced AHPs. The reversal potentials of light-induced and current-induced AHPs pulses were similar, about $-90 \mathrm{mV}$, suggesting that both are mediated by increased potassium conductance.

Overall, the data from ChR2-expressioning PER slices suggest that $10-40 \mathrm{~Hz}$ light trains rapidly excited the majority of pyramidal cells, as identified by morphology and physiological characteristics. This was accomplished either by direct ChR2 activation or indirectly via synaptic events mediated by local circuits. Action potentials in many cells were entrained by the periodic light stimuli. Most neurons, regardless of whether they expressed ChR2, received both excitatory and inhibitory synaptic inputs during stimulation and an interval of membrane hyperpolarization and spike suppression followed trains of light stimuli.

We were also interested in the in vivo effects of optical stimulation on PER neuronal activity and LFPs. Optrodes were im- 

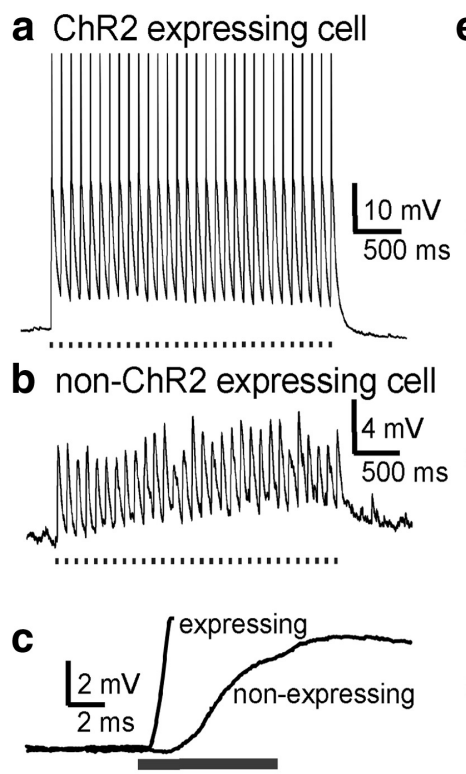

d

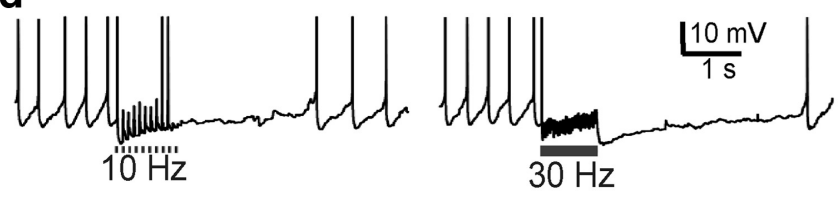

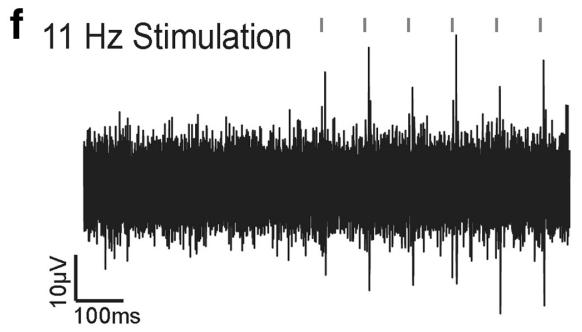
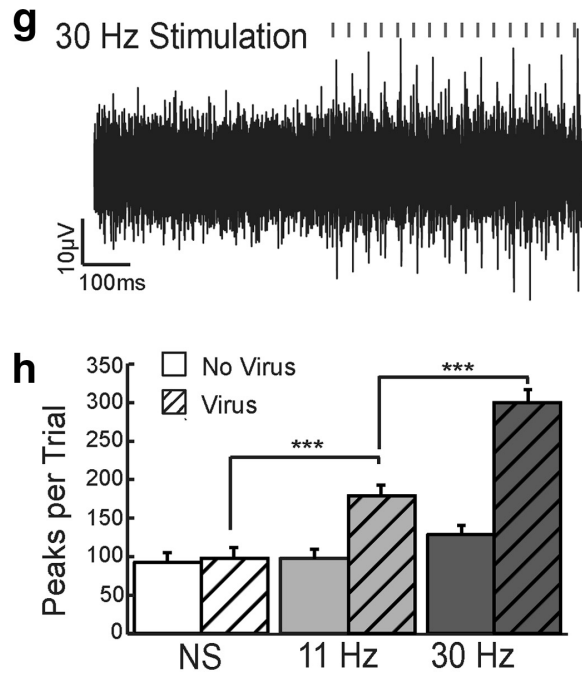

Figure 6. Responses of PER neurons to optical stimulation in vitro and in vivo. $\boldsymbol{a}$, In vitro responses were recorded from 29 cells. Expressing cells generated large amplitude depolarizations with short latencies; one-third of such cells, including this one, reliably generated action potentials. Light stimuli (8 ms pulses) are indicated by tick marks. $\boldsymbol{b}$, Example of synaptic responses to $10 \mathrm{~Hz}$ optical stimulation from a cell that did not express ChR2. c, ChR2-expressing and non-ChR2-expressing neurons were identifiable by the latency of light-evoked changes in membrane potential or current. (d), When steady depolarizing current was used to activate low-frequency spiking in a non-ChR2-expressing neuron, trains of light pulses triggered mixed effects, including stimulus-entrained spikes (at $10 \mathrm{~Hz}$ ), net inhibition of baseline spiking (at $30 \mathrm{~Hz}$ ), and poststimulus hyperpolarization and spike suppression. e, After termination of trains of light stimuli $(10-40 \mathrm{~Hz}$ ) the membrane of most neurons hyperpolarized for durations of $0.5-10 \mathrm{~s}$ (depending on train length and frequency). $\boldsymbol{f}-\boldsymbol{h}$, In vivo activity during optical stimulation in PER. MUA $500 \mathrm{~ms}$ before and $500 \mathrm{~ms}$ during $11 \mathrm{~Hz}(\boldsymbol{f})$ and $30 \mathrm{~Hz}(\boldsymbol{g})$ stimulation in a virally transduced animal. $\boldsymbol{h}$, Spiking activity during stimulation trials (20 trials per condition per rat) shows a frequency-dependent increase in activity during optogenetic stimulation in the transduced group (virus, $n=3$ ), but not in the no virus group $(n=3) .{ }^{* *} p<0.001$. Data are means + SEM.

planted in caudal PER after transduction with ChR2 (virus, $n=$ 3 ) and in normal control rats (no virus, $n=3$ ). MUA was assessed under three optical stimulation conditions: a no stimulation control, stimulation at $11 \mathrm{~Hz}$ ( $8 \mathrm{~ms}$ pulses), and stimulation at $30 \mathrm{~Hz}$ ( $8 \mathrm{~ms}$ pulses). Stimulation trains were $3 \mathrm{~s}$ in duration with $2 \mathrm{~s}$ interstimulus intervals. During stimulation in the virus rats, LFP recordings showed that power increased at the stimulation frequency, but there was no long-lasting change in the LFP or MUA after the offset of stimulation (data not shown). Optical stimulation in the virus animals also induced spiking activity and MUA increased with increasing frequency of optical stimulation (Fig. $6 f-h)$. Importantly, there was no change in MUA during stimulation of PER in the no virus condition, indicating that light artifact is not responsible for our effects. Moreover, there was no difference between virus and no virus animals in baseline MUA, indicating that viral infection does not affect baseline neuronal activity.

\section{Control experiments}

\section{Locomotor activity}

To examine the effect of optical stimulation at 30 and $11 \mathrm{~Hz}$ on locomotor activity, we calculated average running speed (pixels/ $\mathrm{mm}$ ) using a CinePlex V2 tracking system (Plexon) while rats $(n=5)$ freely explored the SOR arena. No images were presented during the trials. Testing consisted of 20 randomized trials of $3 \mathrm{~s}$ duration under no stimulation, $11 \mathrm{~Hz}$ stimulation, and $30 \mathrm{~Hz}$ stimulation conditions with a $2 \mathrm{~s}$ intertrial interval for a total of 60 trials. Light pulses were $8 \mathrm{~ms}$ in duration, as in the primary experiments. A one-way rANOVA was used for comparisons of speed under the stimulation conditions. As shown in Figure $7 a$, average speed (pixels/s) did not differ significantly across the three stimulation conditions $\left(F_{(2,8)}=1.2, p=0.359\right)$. Therefore, optical stimulation of PER did not alter locomotor activity.

\section{Nonspecific effects of amount of light}

Another control experiment provided further evidence that exploratory behavior is modulated by frequency of stimulation and not total light delivered. In the main experiments, we used an 8 ms pulse duration, which has been used reliably to evoke a single spike in prior optogenetic studies (Boyden et al., 2005; Desai et al., 2011). In a control experiment, we examined the effect of total light delivery per bout. As in the main experiments, the experimenter was blind to stimulation condition. We used the $\mathrm{XX} \rightarrow$ $\mathrm{XX}$ paradigm in which exploration of one familiar image is paired with $30 \mathrm{~Hz}$ and exploration of the other identical familiar image is paired with $11 \mathrm{~Hz}$. When pulse widths were $8 \mathrm{~ms}$ for both 30 and $11 \mathrm{~Hz}$ stimulation, we saw significant discrimination (Fig. 2b, bar on the right, Fig. $7 b$, bar on the left). In this control experiment, pulse widths were $4 \mathrm{~ms}$ for the image paired with $30 \mathrm{~Hz}$ and $12 \mathrm{~ms}$ for the image paired with $11 \mathrm{~Hz}$ such that the amount of light energy delivered during looking was approximately equivalent for $30 \mathrm{~Hz}$ and $11 \mathrm{~Hz}$. The DR was similar to the earlier experi- 

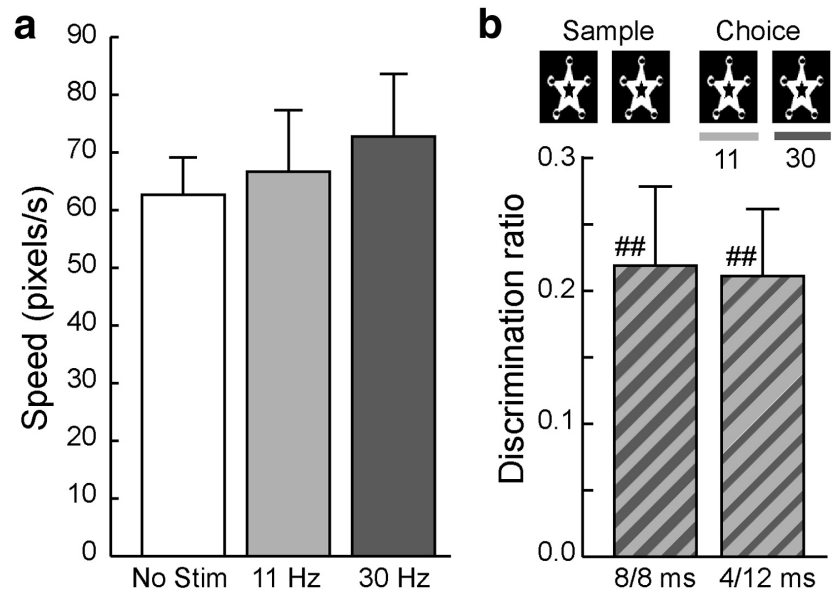

Figure 7. Control experiments for effects on locomotor activity and differences in amount of light delivered. $\boldsymbol{a}, 0$ ptical stimulation at 11 or $30 \mathrm{~Hz}$ had no effect on locomotor activity $(n=5)$. $\boldsymbol{b}$, Controlling for total light between 11 and $30 \mathrm{~Hz}$ conditions by compensating with pulse widths did not affect differential exploration ( $n=6$ for each condition). For both experiments, the $D R=$ (time exploring in $30 \mathrm{~Hz}$ condition - time exploring in the $11 \mathrm{~Hz}$ condition)/(time exploring in $30 \mathrm{~Hz}$ condition + time exploring in the $11 \mathrm{~Hz}$ condition). The bar on the left shows the DR when pulses are $8 \mathrm{~ms}$ for both conditions. The bar on the right shows the DR when $30 \mathrm{~Hz}$ pulses are $4 \mathrm{~ms}$ and $11 \mathrm{~Hz}$ pulses are $12 \mathrm{~ms}$. Data are means \pm normalized SEM. \#\# $<0.01$, significant difference from zero, $p<0.05$ ( $t$ test).

ment, indicating that pulse width does not account for our findings (Fig. $7 b$, bar on the right). This was confirmed by $t$ tests $t_{(5)}=3.7, p=0.01$ for the $8 / 8 \mathrm{~ms}$ experiment and $t_{(5)}=4.2, p<$ 0.01 for the $4 / 12 \mathrm{~ms}$ experiment).

Rats $(n=6)$ preferentially explored the image paired with 30 $\mathrm{Hz}, 4 \mathrm{~ms} /$ pulse stimulation over the image paired with $11 \mathrm{~Hz}, 12$ $\mathrm{ms} /$ pulse stimulation $\left(\mathrm{DR}>0 ; t_{(5)}=4.2, p=0.004\right)$. The $\mathrm{DR}$ for this experiment did not differ significantly from that obtained when the pulse widths were equivalent at $8 \mathrm{~ms}\left(\mathrm{DR}>0 ; t_{(5)}=3.7\right.$; $\left.p=0.007 ; F_{(1,5)}<1, p=0.36\right)$. Furthermore, the total choice exploration time at the adjusted pulse widths $(10.7 \pm 1.7 \mathrm{~s})$ did not differ significantly from that at the $8 \mathrm{~ms}$ pulse widths $(13.9 \pm$ $\left.2.1 \mathrm{~s} ; F_{(1,5)}=1.3, p=0.30\right)$. Exploration bout duration increased significantly with $30 \mathrm{~Hz}, 4 \mathrm{~ms} /$ pulse optical stimulation compared with $11 \mathrm{~Hz}, 12 \mathrm{~ms} /$ pulse $\left(F_{(1,5)}=15.6, p=0.01\right)$, a result also observed when pulse widths were $8 \mathrm{~ms}$. Therefore, differential behavioral effects observed with 30 and $11 \mathrm{~Hz}$ optical stimulation cannot be explained by differences in total light delivery.

\section{Discussion}

The ability to identify novelty and familiarity is important for memory, learning, and adaptive behavior. Identification of familiarity depends on the PER (for review, see Brown and Aggleton, 2001; Eichenbaum et al., 2007), but how novelty and familiarity are encoded and transmitted in the brain is not understood. Using optogenetic methods, we tested whether exploration of novelty and familiarity could be altered differentially by stimulation of the PER at different frequencies. We found that optical stimulation of the same ensemble of ChR2-expressing caudal PER neurons resulted in a striking bidirectional modulation of spontaneous exploratory behavior. Stimulation at $30-40 \mathrm{~Hz}$ increased exploration of familiar images. In contrast, stimulation at $10-15 \mathrm{~Hz}$ decreased exploration of novel images. Modulation of exploratory behavior was expressed primarily as changes in the duration of individual bouts of looking at the images. This is important because longer exploratory bouts are a signature of attention and of novelty exploration (Ennaceur et al., 2009).

Two findings are worth further discussion. Whereas stimulation at $30-40 \mathrm{~Hz}$ increased exploration of familiar images, stimulation at these frequencies had little or no effect on exploration of novel images. Likewise, stimulation at $10-15 \mathrm{~Hz}$ decreased exploration of novel images, but had little or no effect on exploration of familiar images. This suggests that the $30-40 \mathrm{~Hz}$ stimulation of caudal PER does simulate the effects of novelty on exploratory behavior and that the $10-15 \mathrm{~Hz}$ stimulation does simulate the effects of familiarity. This is consistent with an earlier example in which behavioral preferences were modified. Electrical stimulation at different frequencies in the chick hyperstriatum, the region important for imprinting, induced later preference for lights flashing at the frequency of the stimulation (McCabe et al., 1979).

Our in vivo and in vitro electrophysiology experiments yield insight into the mechanisms by which exploratory behavior was modulated. Our in vitro recordings showed that a substantial proportion of ChR2-expressing cells in caudal PER reliably generated action potentials with optical stimulation. Our in vivo electrophysiology experiments showed that stimulation at $11 \mathrm{~Hz}$ or $30 \mathrm{~Hz}$ increased MUA. Examination of individual traces revealed that the increase in spiking activity was largely entrained with optical stimulation. Although our study does not address mechanisms directly or rule out rate coding, synchronous firing in PER is a candidate mechanism for recognition memory. Indeed, in other regions, synchronous activity is implicated in plasticity (for review, see Martin and Morris, 2002; McBain and Kauer, 2009).

Prior studies report that neuronal firing rates in the PER decrease as novel items become familiar (Riches et al., 1991; Fahy et al., 1993; Brown and Xiang, 1998; Xiang and Brown, 1998; Hölscher et al., 2003). If firing rates were monotonically related to novelty exploration, then we would expect to see a monotonic relationship between frequency and exploration (Fig. 4). Instead, 30 and $40 \mathrm{~Hz}$ stimulation increased exploration of familiar images, whereas 20 and $60 \mathrm{~Hz}$ had no effect (Fig. 4b). In addition, 10 and $15 \mathrm{~Hz}$ stimulation decreased exploration of novel images, whereas 5 and $20 \mathrm{~Hz}$ had no effect (Fig. 4a). Interestingly, stimulation at $30-60 \mathrm{~Hz}$ during exploration of novel images had variable effects, suggesting that, if images are already novel, the effects of 30 and $40 \mathrm{~Hz}$ stimulation do not reliably increase exploration. Similarly, stimulation at $11 \mathrm{~Hz}$ during exploration of familiar images had no effect (Figs. $2 c, 7 b$ ), suggesting that, if images are already familiar, $11 \mathrm{~Hz}$ stimulation does not further decrease exploration.

Neuroanatomical studies show that the PER is interconnected with other regions also known to be involved in processing novelty and familiarity (Burwell and Amaral, 1998; Agster and Burwell, 2009), including prefrontal cortex (PFC) (Dias and Honey, 2002; Matsumoto et al., 2007; Kishiyama et al., 2009). Given that the PFC has an identified role in executive function (Dalley et al., 2004), it may be in a position to guide exploratory behavior based on the current context. Medial PFC ensembles of neurons recorded in rats differentiate entire environmental contexts and changes in environmental contexts (Hyman et al., 2012). The PER is most heavily interconnected with the medial PFC and with a subarea of medial agranular PFC (Burwell and Amaral, 1998; Agster and Burwell, 2009). Both of these areas are implicated in attention. Damage to medial PFC impairs the ability to shift attention from one perceptual domain to another (Birrell and Brown, 2000) and damage to medial agranular PFC results in multimodal attentional neglect (King and Corwin, 1992, 1993; 
Burcham et al., 1997; Reep and Corwin, 2009). Interestingly, the latency of PFC neurons to signal repetition is longer than that of PER neurons (Riches et al., 1991; Xiang and Brown, 1998; Xiang and Brown, 2004). Together, our findings suggest a model in which a bidirectional flow of visual information between PER and PFC coordinates exploration of novelty and familiarity. In this model, similar to one proposed recently (Preston and Eichenbaum, 2013), the PER would signal the presence of a novel or familiar item to the PFC. The PFC then would guide exploration of the item based on other information, for example, the relative familiarity of the context.

How might information about novelty and familiarity be transmitted between the PER and PFC? Computational and experimental studies have suggested two general coding mechanisms by which neurons can transmit information across brain regions-: an asynchronous (rate) code and a synchronous (temporal) code (for review, see Kumar et al., 2010). Although both rate and temporal codes certainly coexist (Singer, 2009; Kumar et al., 2010), propagation across brain regions may be more efficiently processed by temporal codes. Fries (2005) proposed the communication-through-coherence hypothesis, which states that neuronal populations communicate most efficiently when they are oscillating in phase. Although our data do not address this hypothesis directly, one possibility is that oscillations or synchronous spiking support transmission of information about novelty and familiarity between the PER and PFC.

To conclude, the PER has a well established role in distinguishing novel from familiar objects, but how novelty and familiarity are encoded and signaled to other brain regions is unknown. In the present study, we were able to modulate exploration of novelty and familiarity by stimulating the PER at different frequencies. We showed that stimulation of the PER at 30-40 $\mathrm{Hz}$ resulted in increased exploration of familiar images as if those images were novel. Stimulation of the PER at $10-15 \mathrm{~Hz}$ resulted in decreased exploration of novel images as if those images were familiar. We propose that, when PER neurons fire in phase at these frequencies, transmission of information about novel and familiar objects or images to and from other brain regions implicated in object recognition memory is enhanced.

\section{References}

Agster KL, Burwell RD (2009) Cortical efferents of the perirhinal, postrhinal, and entorhinal cortices of the rat. Hippocampus 19:1159-1186. CrossRef Medline

Barker GR, Warburton EC (2011) When is the hippocampus involved in recognition memory? J Neurosci 31:10721-10731. CrossRef Medline

Beierlein M, Gibson JR, Connors BW (2003) Two dynamically distinct inhibitory networks in layer 4 of the neocortex. J Neurophysiol 90:29873000. CrossRef Medline

Birrell JM, Brown VJ (2000) Medial frontal cortex mediates perceptual attentional set shifting in the rat. J Neurosci 20:4320-4324. Medline

Boyden ES, Zhang F, Bamberg E, Nagel G, Deisseroth K (2005) Millisecondtimescale, genetically targeted optical control of neural activity. Nat Neurosci 8:1263-1268. CrossRef Medline

Brown MW, Aggleton JP (2001) Recognition memory: what are the roles of the perirhinal cortex and hippocampus? Nat Rev Neurosci 2:51-61. CrossRef Medline

Brown MW, Xiang JZ (1998) Recognition memory: neuronal substrates of the judgement of prior occurrence. Prog Neurobiol 55:149-189. CrossRef Medline

Brown MW, Warburton EC, Aggleton JP (2010) Recognition memory: material, processes, and substrates. Hippocampus 20:1228-1244. CrossRef Medline

Burcham KJ, Corwin JV, Stoll ML, Reep RL (1997) Disconnection of medial agranular and posterior parietal cortex produces multimodal neglect in rats. Behav Brain Res 86:41-47. CrossRef Medline
Burke SN, Maurer AP, Hartzell AL, Nematollahi S, Uprety A, Wallace JL, Barnes CA (2012) Representation of three-dimensional objects by the rat perirhinal cortex. Hippocampus 22:2032-2044. CrossRef Medline

Burwell RD, Amaral DG (1998) Cortical afferents of the perirhinal, postrhinal, and entorhinal cortices of the rat. J Comp Neurol 398:179-205. CrossRef Medline

Bussey TJ, Muir JL, Aggleton JP (1999) Functionally dissociating aspects of event memory: the effects of combined perirhinal and postrhinal cortex lesions on object and place memory in the rat. J Neurosci 19:495-502. Medline

Cousineau D (2005) Confidence interfals in within-subject designer solution to Loftus and Masson's method. Tutor Quant Methods Psychol $1: 42-45$.

Cowell RA, Bussey TJ, Saksida LM (2010) Components of recognition memory: dissociable cognitive processes or just differences in representational complexity? Hippocampus 20:1245-1262. CrossRef Medline

Cruikshank SJ, Urabe H, Nurmikko AV, Connors BW (2010) Pathwayspecific feedforward circuits between thalamus and neocortex revealed by selective optical stimulation of axons. Neuron 65:230-245. CrossRef Medline

Cruikshank SJ, Ahmed OJ, Stevens TR, Patrick SL, Gonzalez AN, Elmaleh M, Connors BW (2012) Thalamic control of layer 1 circuits in prefrontal cortex. J Neurosci 32:17813-17823. CrossRef Medline

Dalley JW, Cardinal RN, Robbins TW (2004) Prefrontal executive and cognitive functions in rodents: neural and neurochemical substrates. Neurosci Biobehav Rev 28:771-784. CrossRef Medline

Debener S, Herrmann CS, Kranczioch C, Gembris D, Engel AK (2003) Topdown attentional processing enhances auditory evoked gamma band activity. Neuroreport 14:683-686. CrossRef Medline

Desai M, Kahn I, Knoblich U, Bernstein J, Atallah H, Yang A, Kopell N, Buckner RL, Graybiel AM, Moore CI, Boyden ES (2011) Mapping brain networks in awake mice using combined optical neural control and fMRI. J Neurophysiol 105:1393-1405. CrossRef Medline

Deshmukh SS, Johnson JL, Knierim JJ (2012) Perirhinal cortex represents nonspatial, but not spatial, information in rats foraging in the presence of objects: comparison with lateral entorhinal cortex. Hippocampus 22: 2045-2058. CrossRef Medline

Dias R, Honey RC (2002) Involvement of the rat medial prefrontal cortex in novelty detection. Behav Neurosci 116:498-503. CrossRef Medline

Dix SL, Aggleton JP (1999) Extending the spontaneous preference test of recognition: evidence of object-location and object-context recognition. Behav Brain Res 99:191-200. CrossRef Medline

Eichenbaum H, Yonelinas AP, Ranganath C (2007) The medial temporal lobe and recognition memory. Annu Rev Neurosci 30:123-152. CrossRef Medline

Ennaceur A, Delacour J (1988) A new one-trial test for neurobiological studies of memory in rats. 1: Behavioral data. Behav Brain Res 31:47-59. CrossRef Medline

Ennaceur A, Michalikova S, Chazot PL (2009) Do rats really express neophobia towards novel objects? Experimental evidence from exposure to novelty and to an object recognition task in an open space and an enclosed space. Behav Brain Res 197:417-434. CrossRef Medline

Fahy FL, Riches IP, Brown MW (1993) Neuronal activity related to visual recognition memory: long-term memory and the encoding of recency and familiarity information in the primate anterior and medial inferior temporal and rhinal cortex. Exp Brain Res 96:457-472. Medline

Forwood SE, Bartko SJ, Saksida LM, Bussey TJ (2007) Rats spontaneously discriminate purely visual, two-dimensional stimuli in tests of recognition memory and perceptual oddity. Behav Neurosci 121:1032-1042. CrossRef Medline

Fries P (2005) A mechanism for cognitive dynamics: neuronal communication through neuronal coherence. Trends Cogn Sci 9:474-480. CrossRef Medline

Fries P (2009) Neuronal gamma-band synchronization as a fundamental process in cortical computation. Annu Rev Neurosci 32:209-224. CrossRef Medline

Gonsalves BD, Kahn I, Curran T, Norman KA, Wagner AD (2005) Memory strength and repetition suppression: multimodal imaging of medial temporal cortical contributions to recognition. Neuron 47:751-761. CrossRef Medline

Hannesson DK, Howland JG, Phillips AG (2004) Interaction between perirhinal and medial prefrontal cortex is required for temporal order but 
not recognition memory for objects in rats. J Neurosci 24:4596-4604. CrossRef Medline

Herrmann CS, Knight RT (2001) Mechanisms of human attention: eventrelated potentials and oscillations. Neurosci Biobehav Rev 25:465-476. CrossRef Medline

Hölscher C, Rolls ET, Xiang J (2003) Perirhinal cortex neuronal activity related to long-term familiarity memory in the macaque. Eur J Neurosci 18:2037-2046. CrossRef Medline

Hyman JM, Ma L, Balaguer-Ballester E, Durstewitz D, Seamans JK (2012) Contextual encoding by ensembles of medial prefrontal cortex neurons. Proc Natl Acad Sci U S A 109:5086-5091. CrossRef Medline

Jacobson TK, Ho JW, Kent BW, Yang FC, Burwell RD (2014) Automated visual cognitive tasks for recording neural activity using a floor projection maze. J Vis Exp 84:e51316. Medline

King VR, Corwin JV (1992) Spatial deficits and hemispheric asymmetries in the rat following unilateral and bilateral lesions of posterior parietal or medial agranular cortex. Behav Brain Res 50:53-68. CrossRef Medline

King VR, Corwin JV (1993) Comparisons of hemi-inattention produced by unilateral lesions of the posterior parietal cortex or medial agranular prefrontal cortex in rats: neglect, extinction, and the role of stimulus distance. Behav Brain Res 54:117-131. CrossRef Medline

Kishiyama MM, Yonelinas AP, Knight RT (2009) Novelty enhancements in memory are dependent on lateral prefrontal cortex. J Neurosci 29:81148118. CrossRef Medline

Kumar A, Rotter S, Aertsen A (2010) Spiking activity propagation in neuronal networks: reconciling different perspectives on neural coding. Nat Rev Neurosci 11:615-627. CrossRef Medline

Lapray D, Bergeler J, Luhmann HJ (2009) Stimulus-induced gamma activity in the electrocorticogram of freely moving rats: the neuronal signature of novelty detection. Behav Brain Res 199:350-354. CrossRef Medline

Lee B, Park KS, Kang DH, Kang KW, Kim YY, Kwon JS (2007) Generators of the gamma-band activities in response to rare and novel stimuli during the auditory oddball paradigm. Neurosci Lett 413:210-215. CrossRef Medline

Lehky SR, Tanaka K (2007) Enhancement of object representations in primate perirhinal cortex during a visual working-memory task. J Neurophysiol 97:1298-1310. Medline

Lulham A, Bogacz R, Vogt S, Brown MW (2011) An Infomax algorithm can perform both familiarity discrimination and feature extraction in a single network. Neural Comput 23:909-926. CrossRef Medline

Mandler G (1980) Recognizing: the judgement of prior occurrence. Psychol Rev 87:252-271. CrossRef

Marco-Pallarés J, Münte TF, Rodríguez-Fornells A (2015) The role of highfrequency oscillatory activity in reward processing and learning. Neurosci Biobehav Rev 49:1-7. CrossRef Medline

Martin SJ, Morris RG (2002) New life in an old idea: the synaptic plasticity and memory hypothesis revisited. Hippocampus 12:609-636. CrossRef Medline

Matsumoto M, Matsumoto K, Tanaka K (2007) Effects of novelty on activity of lateral and medial prefrontal neurons. Neurosci Res 57:268-276. CrossRef Medline

McBain CJ, Kauer JA (2009) Presynaptic plasticity: targeted control of inhibitory networks. Curr Opin Neurobiol 19:254-262. CrossRef Medline

McCabe BJ, Horn G, Bateson PP (1979) Effects of rhythmic hyperstriatal stimulation on chicks' preferences for visual flicker. Physiol Behav 23: 137-140. CrossRef Medline

Meunier M, Bachevalier J, Mishkin M, Murray EA (1993) Effects on visual recognition of combined and separate ablations of the entorhinal and perirhinal cortex in rhesus monkeys. J Neurosci 13:5418-5432. Medline

Montaldi D, Spencer TJ, Roberts N, Mayes AR (2006) The neural system that mediates familiarity memory. Hippocampus 16:504-520. CrossRef Medline
Mumby DG, Pinel JP (1994) Rhinal cortex lesions and object recognition in rats. Behav Neurosci 108:11-18. CrossRef Medline

Nagel G, Szellas T, Huhn W, Kateriya S, Adeishvili N, Berthold P, Ollig D, Hegemann P, Bamberg E (2003) Channelrhodopsin-2, a directly lightgated cation-selective membrane channel. Proc Natl Acad Sci U S A 100: 13940-13945. CrossRef Medline

Naya Y, Yoshida M, Miyashita Y (2001) Backward Spreading of MemoryRetrieval Signal in the Primate Temporal Cortex. Science 291:661-664. CrossRef Medline

Nerad L, Bilkey DK (2005) Ten- to 12-Hz EEG oscillation in the rat hippocampus and rhinal cortex that is modulated by environmental familiarity. J Neurophysiol 93:1246-1254. Medline

Park J, Lee H, Kim T, Park GY, Lee EM, Baek S, Ku J, Kim IY, Kim SI, Jang DP, Kang JK (2014) Role of low- and high-frequency oscillations in the human hippocampus for encoding environmental novelty during a spatial navigation task. Hippocampus 24:1341-1352. CrossRef Medline

Preston AR, Eichenbaum H (2013) Interplay of hippocampus and prefrontal cortex in memory. Curr Biol 23:R764-R773. CrossRef Medline

Reep RL, Corwin JV (2009) Posterior parietal cortex as part of a neural network for directed attention in rats. Neurobiol Learn Mem 91:104-113. CrossRef Medline

Renner MJ, Seltzer CP (1991) Molar characteristics of exploratory and investigatory behavior in the rat (Rattus norvegicus). J Comp Psychol 105: 326-339. CrossRef Medline

Riches IP, Wilson FA, Brown MW (1991) The effects of visual stimulation and memory on neurons of the hippocampal formation and the neighboring parahippocampal gyrus and inferior temporal cortex of the primate. J Neurosci 11:1763-1779. Medline

Sato N, Nakamura K (2003) Visual response properties of neurons in the parahippocampal cortex of monkeys. J Neurophysiol 90:876-886. CrossRef Medline

Singer W (2009) Distributed processing and temporal codes in neuronal networks. Cogn Neurodyn 3:189-196. CrossRef Medline

Thome A, Erickson CA, Lipa P, Barnes CA (2012) Differential effects of experience on tuning properties of macaque MTL neurons in a passive viewing task. Hippocampus 22:2000-2011. CrossRef Medline

Wan H, Aggleton JP, Brown MW (1999) Different contributions of the hippocampus and perirhinal cortex to recognition memory. J Neurosci 19: 1142-1148. Medline

Winters BD, Forwood SE, Cowell RA, Saksida LM, Bussey TJ (2004) Double dissociation between the effects of peri-postrhinal cortex and hippocampal lesions on tests of object recognition and spatial memory: heterogeneity of function within the temporal lobe. J Neurosci 24:5901-5908. CrossRef Medline

Winters BD, Saksida LM, Bussey TJ (2008) Object recognition memory: neurobiological mechanisms of encoding, consolidation and retrieval. Neurosci Biobehav Rev 32:1055-1070. CrossRef Medline

Xiang JZ, Brown MW (1998) Differential neuronal encoding of novelty, familiarity and recency in regions of the anterior temporal lobe. Neuropharmacology 37:657-676. CrossRef Medline

Xiang JZ, Brown MW (2004) Neuronal responses related to long-term recognition memory processes in prefrontal cortex. Neuron 42:817-829. CrossRef Medline

Yanike M, Wirth S, Smith AC, Brown EN, Suzuki WA (2009) Comparison of associative learning-related signals in the macaque perirhinal cortex and hippocampus. Cereb Cortex 19:1064-1078. CrossRef Medline

Young BJ, Otto T, Fox GD, Eichenbaum H (1997) Memory representation within the parahippocampal region. J Neurosci 17:5183-5195. Medline

Zhu XO, Brown MW, Aggleton JP (1995) Neuronal signalling of information important to visual recognition memory in rat rhinal and neighbouring cortices. Eur J Neurosci 7:753-765. CrossRef Medline 